\title{
The use of antiviral drugs for influenza: Guidance for practitioners 2012/2013
}

\author{
Fred Y Aoki MD FRCPC ${ }^{1}$, Upton D Allen MBBS MSc FAAP FRCPC ${ }^{2,3,4}$, H Grant Stiver MD FRCPC ${ }^{5}$, Gerald A Evans MD FRCPC ${ }^{6,7}$
}

\begin{abstract}
FY Aoki, UD Allen, HG Stiver, GA Evans. The use of antiviral drugs for influenza: Guidance for practitioners 2012/2013. Can J Infect Dis Med Microbiol 2012;23(4):e79-e92.
\end{abstract}

The present article addresses the use of antiviral drugs in the management of seasonal influenza illness for the 2012/2013 season. It updates the previous document published in 2011 (1). Noteworthy guidance updates since 2011 include the following:

- Seasonal influenza in 2012/2013 is predicted to be caused by two human influenza A and one influenza B strain, all of which are anticipated to remain generally susceptible to oseltamivir.

- The predicted strains are A/California/7/2009 (H1N1) pdm09. like, A/Victoria/361/2011 (H3N2)-like and B/Wisconsin/1/2010. like (Yamagata lineage). All are included in the seasonal influenza vaccine and are susceptible to oseltamivir.

- Swine-variant H3N2v, which has rarely caused infection in humans exposed to infected swine within the past year in the United States, is susceptible to oseltamivir. It is not included in the current seasonal influenza vaccine.

- It is still considered that initiation of antiviral therapy more than $36 \mathrm{~h}$ to $48 \mathrm{~h}$ after onset of symptoms is beneficial in patients hospitalized with complicated influenza and severe illness.

- Oseltamivir continues to be recommended for the treatment of influenza in pregnant women.

- The use of antiviral drugs among measures to control outbreaks of influenza in closed facilities such as correctional institutions is now included in the present document.

\section{L'utilisation d'antiviraux contre l'influenza : des conseils pour les praticiens en 2012-2013}

Le présent article porte sur l'utilisation d'antiviraux pour prendre en charge l'influenza pendant la saison 2012-2013. Il met à jour le document publié en 2011 (1). Les conseils qui méritent d'être soulignés depuis 2011 s'établissent comme suit :

- On prévoit qu'en 2012-2013, l'influenza saisonnière sera causée par deux souches de l'influenza humaine A et une souche de l'influenza B, qui devraient demeurer généralement susceptibles à l'oseltamivir.

- Les souches prévues sont le virus analogue à A/California/7/2009 (H1N1)pdm09, le virus analogue à A/Victoria/361/2011 (H3N2) et le virus analogue à $\mathrm{B} / \mathrm{Wisconsin} / 1 / 2010$ (lignée Yamagata). Toutes sont incluses dans le vaccin contre l'influenza saisonnière et sont susceptibles à l'oseltamivir.

- La variante porcine du virus H3N2 (H3N2v), qui a causé peu d'infections chez des humains exposés à des porcs depuis un an aux États-Unis, est susceptible à l'oseltamivir. Elle n'est pas incluse dans le vaccin actuel contre l'influenza saisonnière.

- On considère encore que l'amorce des antiviraux plus de 36 heures à 48 heures après l'apparition des symptômes est bénéfique aux patients hospitalisés en raison d'une influenza complexe et d'une maladie grave.

- L'oseltamivir continue d'être recommandé pour le traitement de l'influenza chez les femmes enceintes.

- Le recours à des antiviraux parmi les mesures de contrôle des éclosions d'influenza dans des établissements fermés, tels que les établissements de détention, fait désormais partie de ce document.
$\mathrm{T}$ he purpose of the present document is to provide recommendations for clinicians regarding the use of antiviral drugs for the prevention and treatment of influenza during the 2012/2013 influenza season in Canada. Other aspects of influenza management, such as laboratory diagnosis, infection control, immunization and nonpharmacological interventions, are beyond the scope of the present article. The present article is an update of our document that was published in 2011 (1).

\section{GRADING OF RECOMMENDATIONS}

A grading system is used to qualify recommendations based on the quality of evidence and the determination of benefit versus harm arising from the recommendation as defined below (2). In situations where high-quality evidence is not available but anticipated benefits strongly outweigh the harm, the recommendation could be based on lesser evidence. Categories of evidence and their relationship to recommendations are outlined in Table 1.

Definitions of the strength of evidence for the recommendations Strong recommendation: Benefits of treatment approach clearly exceed harms; quality of evidence is high (Grade A), moderate (Grade B) or exceptional (Grade X).

Recommendation: Benefits exceed harm, but quality of evidence is moderate (Grade B), low (Grade C) or exceptional (Grade X).

Option: Quality of evidence is very low (Grade D) or well-performed studies (Grade A, B or C) show little clear advantage.

No recommendation: There is a lack of pertinent evidence or quality is very low, and there is an unclear balance between benefits and harms.

Impact of recommendation strength on practicing clinicians 'Strong recommendations' should be followed unless a clear and compelling reason for an alternative approach is present. 'Recommendations' should generally be followed, but clinicians should remain alert to new information and patient preferences. 'Option' reflects flexibility in decision making regarding treatment according to the judgment of the clinician. Patient preference should play a substantial influencing role. 'No recommendation' reflects no constraints on decision making, and clinicians should remain alert to new evidence that clarifies the balance of benefit and harm. Patient preference should play a substantial influencing role.

${ }^{1}$ Department of Medicine, Medical Microbiology and Pharmacology $\mathbb{E}$ Therapeutics Faculty of Medicine, University of Manitoba, Winnipeg, Manitoba; ${ }^{2}$ Department of Pediatrics $\mathcal{E}$ Institute of Health Policy, Management and Evaluation; ${ }^{3}$ Research Institute; ${ }^{4}$ Division of Infectious Diseases, Department of Pediatrics, The Hospital for Sick Children, University of Toronto, Toronto, Ontario; ${ }^{5}$ Division of Infectious Diseases, Department of Medicine, University of British Columbia,Vancouver, British Columbia; ${ }^{6}$ Biomedical Eु Molecular Sciences and Pathology E̊ Molecular Medicine; 'Division of Infectious Diseases, Department of Medicine, Kingston General Hospital, Queen's University, Kingston, Ontario

Correspondence: Dr Gerald A Evans, Division of Infectious Diseases, Department of Medicine, Room 3013, Etherington Hall, Queen's University, Kingston, Ontario K7L 3N6 


\section{TABLE 1}

\section{GRADE evidence quality versus benefit-to-harm ratio and} recommendation grading

\begin{tabular}{|l|r|l|}
\hline Quality of evidence & $\begin{array}{c}\text { Preponderance of } \\
\text { benefit or harm }\end{array}$ & $\begin{array}{c}\text { Balance of } \\
\text { benefit and harm }\end{array}$ \\
\hline $\begin{array}{c}\text { A.Well-designed RCTs or } \\
\text { diagnostic studies on } \\
\text { relevant populations }\end{array}$ & recommendation \\
\cline { 1 - 2 } $\begin{array}{c}\text { B.RCTs or diagnostic studies } \\
\text { with minor limitations; } \\
\text { overwhelmingly consistent } \\
\text { evidence from } \\
\text { observational studies }\end{array}$ & Option \\
\cline { 1 - 2 } $\begin{array}{c}\text { C.Observational studies (case } \\
\text { control or cohort design) }\end{array}$ & Recommendation & No \\
\hline $\begin{array}{l}\text { D.Expert opinion, case } \\
\text { reports, reasoning from first } \\
\text { principles }\end{array}$ & Option & Recommendation \\
\hline $\begin{array}{l}\text { X.Exceptional situations } \\
\text { where validating studies } \\
\text { cannot be performed } \\
\text { and there is a clear } \\
\text { preponderance of benefit or } \\
\text { harm }\end{array}$ & Recommendation & \\
\hline
\end{tabular}

Data from reference 2. GRADE Grading of Recommendation, Assessment, Development and Evaluation; RCTs Randomized controlled trials

\section{THE DISEASE}

\section{Influenza viruses}

For the 2012/2013 influenza season, it is expected that the circulating influenza strains will be those contained in the trivalent inactivated influenza vaccines for 2012/2013: A/California/7/2009 (H1N1) pdm09. like, A/Victoria/361/2011 (H3N2)-like and B/Wisconsin/1/2010. like (Yamagata lineage) (3). The former pandemic H1N1 A/ California/07/2009 is now referred to by the WHO, and hereafter, as A(H1N1)pdm09 (4). In Canada, during the 2011/2012 influenza season, influenza B strains predominated. In an analysis of 1443 influenza isolates that were antigenically characterized, $257(18 \%)$ were $\mathrm{A} / \mathrm{H} 3 \mathrm{~N} 2$, $221(15 \%)$ were $\mathrm{A} / \mathrm{H} 1 \mathrm{~N} 1$ and 965 (67\%) were influenza B viruses (5). As usual, the influenza strain that will predominate in Canada this season is uncertain.

Relative to influenza A, influenza B viruses cause proportionately more illness in children than in adults (6). In Canada, over a 12-month period from August 2011 to August 2012, for each age group, more isolates of influenza A were obtained from adults compared with influenza B. Correspondingly, more isolates of influenza B were obtained from children compared with influenza A. Indeed, 21\% of 5197 influenza B isolates were obtained from children younger than five years of age, and $25 \%$ from persons five to 19 years of age; the corresponding percentages of influenza A isolates were $20 \%$ and $11 \%$, respectively (5).

Antiviral drug resistance patterns of influenza viruses demonstrated in vitro generally correlate with treatment outcomes. No influenza A or B viruses isolated from Canadian patients during the 2011/2012 influenza season from September 2011 to August 2012 were resistant to oseltamivir or zanamivir: $256 \mathrm{H} 3 \mathrm{~N} 2,256 \mathrm{H} 1 \mathrm{~N} 1$ and 967 influenza B isolates were tested. More than $99 \%$ of influenza A viruses were resistant to amantadine (5). The same antiviral resistance patterns were reported by the Centers for Disease Control and Prevention (Georgia, USA) in viruses collected domestically and globally (7). Based on these in vitro data, oseltamivir and zanamivir are likely to continue to be similarly efficacious in the management of influenza this season.

The susceptibility of current seasonal influenza viruses to the neuraminidase inhibitor (NAI) drugs oseltamivir and zanamivir, and amantadine are shown in Table 2 (7). Because all of these strains (A/ $\mathrm{H} 1 \mathrm{~N} 1, \mathrm{~A} / \mathrm{H} 3 \mathrm{~N} 2$, influenza B) are resistant to amantadine, subsequent discussion is limited to the NAI drugs.
TABLE 2

Susceptibility of influenza viruses to oseltamivir, zanamivir and amantadine as of December 2011

\begin{tabular}{lccc}
\hline Influenza & Oseltamivir & Zanamivir & Amantadine \\
\hline $\mathrm{A}(\mathrm{H} 1 \mathrm{~N} 1)$ pdm09 & $\mathrm{S}$ & $\mathrm{S}$ & $\mathrm{R}$ \\
Seasonal A/H3N2 & $\mathrm{S}$ & $\mathrm{S}$ & $\mathrm{R}$ \\
Influenza B & $\mathrm{S}$ & $\mathrm{S}$ & $\mathrm{R}$ \\
\hline
\end{tabular}

Data from reference 7. $R$ Resistant; S Susceptible

\section{Clinical aspects}

Seasonal influenza A viruses share similar clinical features. Virus is transmitted from infected to susceptible persons through respiratory secretions containing suspensions of virus, especially airborne droplets generated by coughing and sneezing. The relative contributions of small particle aerosols and fomites in transmission are uncertain. The basic reproductive number $\left(R_{0}\right)$ (mean number of secondary cases transmitted by a single index case to susceptible contacts) ranges from 1.3 to 1.7. The incubation period of seasonal influenza A illness is one to four days, with a mean of two days (8).

In otherwise healthy patients with uncomplicated illness, virus in nasopharyngeal secretions is shed beginning $24 \mathrm{~h}$ (one day) before onset of symptoms, peaks in the first two to three days of illness and declines over five to seven days, although it is commonly accepted that some persons, particularly young children and immunocompromised persons, may shed virus for longer periods (9). For purposes of postexposure prophylaxis (PEP), the infectious period is considered to extend from one day before onset of symptoms until $24 \mathrm{~h}$ after fever ends.

Illness caused by influenza virus can range from asymptomatic to mild, uncomplicated, self-limited upper respiratory tract infection to serious complicated illness dominated by exacerbation of a comorbid, underlying medical condition or severe viral lower respiratory tract infection (pneumonia) with or without multiorgan failure (8).

In adults, influenza typically begins with fever, respiratory symptoms such as cough or sore throat and systemic symptoms such as myalgia, arthralgia and headache. Gastrointestinal symptoms, notably diarrhea, have been described uncommonly as manifestations of seasonal influenza A.

While the typical clinical features of influenza illness appear in older children and youth, among patients younger than 10 years of age, the clinical features may be atypical. Indeed, among children younger than five years of age, influenza illness is often nonspecific and may be indistinguishable from illness due to other respiratory viruses. Young infants may present with a sepsis-like picture. Infants younger than six months of age are more likely to present with rhinorrhea and dehydration than cough and pneumonia and, among those younger than three months of age, fever alone or fever with dehydration are common presenting features (8). Diarrheal illness may be observed. Some clinical signs in infants, children and youth warrant urgent medical attention. Familiarity with these signs is advised (Table 3).

Severe lower respiratory tract disease encompasses diffuse primary viral pneumonia, which often develops directly from progression of initial symptoms, and a secondary bacterial pneumonia, which may arise after a period of initial improvement. Acute respiratory distress syndrome may develop several days after illness onset. The importance of secondary bacterial infections in influenza is further illustrated by the fact that among fatal cases of $\mathrm{A}(\mathrm{H} 1 \mathrm{~N} 1) \mathrm{pdm} 09$, concomitant bacterial pneumonia was demonstrated in $26 \%$ to $38 \%$ of cases (10). These bacteria included Streptococcus pneumoniae, methicillin-susceptible Staphylococcus aureus and methicillin-resistant $S$ aureus.

Influenza-related complications in infants, children and youth include severe hemorrhagic viral pneumonia, secondary bacterial pneumonia (due to $S$ pneumoniae, $S$ aureus or group A streptococcus), mixed viral and bacterial pneumonia, localized viral pneumonia, severe laryngotracheobronchitis (croup) and exacerbation of chronic pulmonary disease. Nonpulmonary complications include acute myositis, myocarditis or pericarditis, toxic shock-like picture (due to 
TABLE 3

Clinical signs warranting urgent medical attention in infants, children and youth with suspected or proven influenza

Infants and toddlers ( $<1$ year and 1-3 years of age, respectively)

Rapid breathing and difficulty breathing

Bluish skin colour or change in skin colour

Not drinking enough fluids

Not waking up or not interacting

Being so irritable that child does not want to be held

Flu-like symptoms improve but then return with fever and a worse cough

Fever with a rash

Seizures

Children and youth ( $>3$ to $<12$ years and $12-18$ years of age, respectively)

Rapid breathing, difficulty breathing or shortness of breath

Bluish skin colour, bloody or coloured sputum

Flu-like symptoms improve but then return with fever and a worse cough

Confusion, listlessness, altered consciousness

Severe or persistent vomiting

Fever with a rash

Severe chest pain or abdominal pain

Seizures

secondary bacterial infection) and neurological complications. The latter include febrile seizures, status epilepticus, encephalitis/encephalopathy, Reye's syndrome and Guillain-Barré syndrome (11).

Conditions that place individuals (including infants, children and youth) at risk of severe outcomes from influenza illness are shown in Table 4, which is adapted from the Canadian National Advisory Committee on Immunization (12) and incorporates recently published data (13).

Clinical diagnosis of influenza illness

Clinical suspicion and the accuracy of diagnosis vary substantially. However, when influenza is circulating in the community, the presence of cough and a fever of $37.8^{\circ} \mathrm{C}$ or higher in otherwise healthy adults has a positive predictive value of $86.8 \%$ for a laboratory-confirmed diagnosis of influenza, although the negative predictive value is poor $(39.3 \%)$ (14). Among nonimmunized young healthy adults, the combination of a fever of $37.8^{\circ} \mathrm{C}$ or higher plus at least one respiratory symptom (sore throat, cough or nasal symptoms) and one constitutional symptom (myalgia, headache, sweats, chills or fatigue) are predictive of influenza confirmed by laboratory testing in $60 \%$ to $71 \%$ of cases $(14-16)$. Among immunized patients 60 years of age and older, the combination of fever, coughing and acute onset have a predictive value of $44 \%$ for laboratory-confirmed diagnosis of influenza (17).

Diagnosing influenza illness by clinical criteria in children is more problematic than in adults because they cannot articulate their symptoms as readily. Studies evaluating the sensitivity and specificity of a clinical diagnosis of influenza in children compared with a laboratory gold standard are limited (18). The common presenting findings of fever, cough and rhinorrhea do not distinguish influenza illness from that due to other respiratory viruses. Thus, in diagnosing influenza in a patient and arriving at a treatment decision, practitioners should be guided by knowledge of whether influenza virus is circulating in their community as well as their clinical assessment of the individual patient, taking into account factors that may influence the presentation such as extremes of age, comorbid conditions and immunocompetence.

\section{TREATMENT OF INFLUENZA ILLNESS}

Antiviral drugs, including off-label use

For both zanamivir and oseltamivir, the present guidelines are recommending some uses that are off-label and not approved by Health
TABLE 4

At-risk groups and comorbid medical conditions that predispose to severe influenza illness

- Asthma and other chronic pulmonary disease, including bronchopulmonary dysplasia, cystic fibrosis, chronic bronchitis and emphysema

- Cardiovascular disease (excluding isolated hypertension; including congenital and acquired heart disease such as congestive heart failure and symptomatic coronary artery disease)

- Malignancy

- Chronic renal insufficiency

- Diabetes mellitus and other metabolic diseases

- Hemoglobinopathies such as sickle cell disease

- Immunosuppression or immunodeficiency due to disease (eg, HIV infection, especially if CD4 count is $<200 \times 10^{6} / \mathrm{L}$ ), or iatrogenic, due to medication

- Neurological disease and neurodevelopmental disorders that compromise handling of respiratory secretions (cognitive dysfunction, spinal cord injury, seizure disorders, neuromuscular disorders, cerebral palsy, metabolic disorders)

- Children younger than five years of age*

- Individuals 65 years of age or older

- People of any age who are residents of nursing homes or other chronic care facilities

- Pregnant women and women up to two weeks postpartum regardless of how the pregnancy ended

- Individuals $<18$ years of age who are on chronic acetylsalicylic acid therapy

- Morbid obesity (body mass index $\geq 40 \mathrm{~kg} / \mathrm{m}^{2}$ )

- Aboriginal peoples

Adapted from references 12 and 13. *Children who are two years through four years of age have a higher rate of complications compared with older children; however, the risk for these children is lower than the risk for children younger than two years of age

Canada. Accordingly, it remains incumbent on the prescribing clinician to apprise the patient that the drug has not been approved for this indication.

Oseltamivir: The NAI drug oseltamivir (Tamiflu, Hoffman-La Roche Ltd, Canada) is authorized by Health Canada for the treatment of uncomplicated influenza in patients one year of age or older who have been symptomatic for no more than two days. Oseltamivir is also authorized in Canada for prevention of influenza in adults and children older than one year of age who are close contacts of an individual with characteristic symptoms of influenza.

Oseltamivir is formulated as oseltamivir phosphate in capsules containing $30 \mathrm{mg}, 45 \mathrm{mg}$ or $75 \mathrm{mg}$ per capsule or as a suspension at a concentration of $6 \mathrm{mg} / \mathrm{mL}$ or $12 \mathrm{mg} / \mathrm{mL}$. No injectable formulation is currently authorized for use.

Oseltamivir phosphate is well absorbed and extensively converted by hepatic and intestinal epithelial cells to oseltamivir carboxylate, which is the active antiviral molecule. It is eliminated almost completely as unchanged drug in the urine by glomerular filtration and renal tubular secretion (19).

In part due to lack of further metabolic transformation, oseltamivir carboxylate has little potential for drug-drug interactions and this expectation has been borne out by limited clinical studies.

Influenza B viruses are approximately 10 - to 20 -fold less susceptible to oseltamivir carboxylate than are influenza A viruses (19), and these in vitro differences may explain differences in clinical efficacy of oseltamivir for treatment of influenza $\mathrm{A}$ and $\mathrm{B}$ virus infections in children $(20,21)$ and adults (22).

Treatment and prophylaxis regimens of oseltamivir and zanamivir for adults and for children according to age and weight are detailed in Table 5 (23). Doses do not need to be adjusted in obese adults (24). Dose reduction is advised for pharmacokinetic reasons in persons with 
TABLE 5

Oseltamivir and zanamivir treatment of influenza in children and youth (<18 years of age) - October 2012

\begin{tabular}{|c|c|c|}
\hline Medication & Treatment (5 days) & Chemoprophylaxis (10 days) \\
\hline \multicolumn{3}{|l|}{ Oseltamivir* } \\
\hline Adults & 75 mg twice daily & 75 mg once daily \\
\hline \multicolumn{3}{|l|}{ Children $\geq 12$ months } \\
\hline$\leq 15$ & $30 \mathrm{mg}$ twice daily & $30 \mathrm{mg}$ once daily \\
\hline$>33$ to 51 & $45 \mathrm{mg}$ twice daily & 45 mg once daily \\
\hline$>51$ to 88 & $60 \mathrm{mg}$ twice daily & 60 mg once daily \\
\hline Children 3 months to $<12$ months $^{\dagger}$ & $3 \mathrm{mg} / \mathrm{kg} /$ dose twice daily & $3 \mathrm{mg} / \mathrm{kg} /$ dose once per day \\
\hline Children $<3$ months ${ }^{\ddagger}$ & $3 \mathrm{mg} / \mathrm{kg} /$ dose twice daily & $\begin{array}{l}\text { Not recommended unless situation judged critical due to } \\
\text { limited data on use in this age group }\end{array}$ \\
\hline \multicolumn{3}{|l|}{ Zanamivir $^{\S}$} \\
\hline Adults & $10 \mathrm{mg}$ (two $5 \mathrm{mg}$ inhalations) twice daily & $10 \mathrm{mg}$ (two $5 \mathrm{mg}$ inhalations) once daily \\
\hline Children ( $\geq 7$ years) & $10 \mathrm{mg}$ (two $5 \mathrm{mg}$ inhalations) twice daily & $10 \mathrm{mg}$ (two $5 \mathrm{mg}$ inhalations) once daily \\
\hline
\end{tabular}

creatinine clearance $<60 \mathrm{~mL} / \mathrm{min}$, although the drug has a wide margin of safety and causes no serious, dose-related adverse effects. Dose reduction is advised for patients with impaired renal function (Table 6) (25-28).

Oral oseltamivir is generally well tolerated. Mild, rapidly reversible nausea and/or vomiting have been observed in approximately $5 \%$ to $10 \%$ more persons taking oseltamivir versus placebo. Nausea and/or vomiting are more common in young adults taking $150 \mathrm{mg}$ twice daily ( $12 \%$ to $15 \%$ ) than $75 \mathrm{mg}$ twice daily ( $8 \%$ to $11 \%$ ) compared with placebo (3\% to $7 \%$ ) (19). Influenza A and B viruses rarely cause central nervous system symptoms such as convulsions and coma (29). A causal relationship between oseltamivir and such adverse effects or a wider spectrum including delirium with hallucinations has not been definitively established $(30,31)$. Close monitoring of treated patients is advised (23).

For adults with seasonal influenza illness of less than $36 \mathrm{~h}$ duration, there appears to be no advantage of combining oseltamivir and zanamivir (32). Administering higher doses of oseltamivir to critically ill patients with influenza is not warranted. Oseltamivir was used to treat critically ill patients during the 2009 H1N1 pandemic. Such use included treatment with higher doses administered for longer periods than the approved five-day regimen of $75 \mathrm{mg}$ twice daily. In critically ill ventilated patients with $\mathrm{A}(\mathrm{H} 1 \mathrm{~N} 1) \mathrm{pdm09}$, oseltamivir administered via a gastric tube was well absorbed, yielding plasma concentrations that exceed the inhibitory concentration of influenza A virus (33). Preliminary analysis from a randomized comparison of $150 \mathrm{mg}$ twice daily and $75 \mathrm{mg}$ twice daily oseltamivir for treatment of patients seriously ill with influenza, including A(H1N1)pdm09 viruses, suggested that the higher dose was safe but offered no benefit over the standard dose regimen, as evaluated by reductions in viral shedding at day 5 of treatment (34).

More details regarding safety, tolerance, drug interactions and formulations were detailed in our previous guideline (1).

Zanamivir: Zanamivir (Relenza, GlaxoSmithKline Inc, United Kingdom) is authorized by Health Canada for the treatment of uncomplicated influenza in patients seven years of age or older who have been symptomatic for no more than two days. It is also authorized for the prevention of influenza in patients seven years of age or older.

In vitro, influenza $A$ and $B$ viruses exhibit similar susceptibility to zanamivir (19). In observational studies of children and young adults with influenza A or B virus infection treated with either oseltamivir or zanamivir, there was no difference in duration of fever between treatments in young children four to 16 years of age (21). However, in older children and adults (mean $[ \pm$ SD] age $15 \pm 12$ years) with influenza $B$ virus infection, the duration of fever was significantly shorter in individuals treated with zanamivir versus oseltamivir (22). In a small, observational study involving persons of unspecified age directly comparing the efficacy of zanamivir in ill persons with influenza A or influenza B virus infection, no differences in duration of fever were observed (35).

No data are available on the comparative effects of oseltamivir and zanamivir on influenza B virus infection in older adults and those in high-risk groups.

Zanamivir is marketed as a powder in a proprietary inhalational device that delivers $5 \mathrm{mg}$ of zanamivir per inhalation (34). 
TABLE 6

Recommended oseltamivir regimens for prevention and treatment of adult patients with renal impairment

\begin{tabular}{lll}
\hline Creatinine clearance & Treatment for five days & Prophylaxis until outbreak is over \\
\hline$>60 \mathrm{~mL} / \mathrm{min}$ & $75 \mathrm{mg}$ twice daily & $75 \mathrm{mg}$ once daily \\
$>30 \mathrm{~mL} / \mathrm{min}-60 \mathrm{~mL} / \mathrm{min}$ & $75 \mathrm{mg}$ once daily OR $30 \mathrm{mg}$ suspension twice daily & $75 \mathrm{mg}$ on alternate days or $30 \mathrm{mg}$ once daily \\
& OR $30 \mathrm{mg}$ capsule twice daily & \\
$10 \mathrm{~mL} / \mathrm{min}-30 \mathrm{~mL} / \mathrm{min}$ & $30 \mathrm{mg}$ once daily & $30 \mathrm{mg}$ on alternate days \\
$<10 \mathrm{~mL} / \mathrm{min}($ renal failure) & Single $75 \mathrm{mg}$ dose for the duration of illness & No data \\
Dialysis patients,+ & & \\
Low-flux hemodialysis & $30 \mathrm{mg}$ after each dialysis session & $30 \mathrm{mg}$ after alternate dialysis sessions \\
High-flux hemodialysis & $75 \mathrm{mg}$ after each dialysis session & No data \\
CAPD dialysis & $30 \mathrm{mg}$ once weekly & $30 \mathrm{mg}$ once weekly \\
CRRT high-flux dialysis & $30 \mathrm{mg}$ daily or $75 \mathrm{mg}$ every second day & No data \\
\hline
\end{tabular}

*Experience with the use of oseltamivir in patients with renal failure is limited. These regimens have been suggested based on the limited available data (26-28). Consultation with an infectious physician or clinical pharmacist is recommended; ${ }^{\dagger}$ The following dosing regimen has been suggested for children based on limited data (28): After alternate hemodialysis sessions in children older than one year of age; after each hemodialysis session (7.5 mg for children weighing >15 kg; $10 \mathrm{mg}$ for children weighing $16 \mathrm{~kg}$ to $23 \mathrm{~kg} ; 15 \mathrm{mg}$ for children weighing $24 \mathrm{~kg}$ to $40 \mathrm{~kg}$, and $30 \mathrm{mg}$ for children weighing $>40 \mathrm{~kg}$ ). While this may provide a framework for guidance, it is strongly recommended that an infectious disease physician or clinical pharmacist be consulted. CAPD Continuous ambulatory peritoneal dialysis; CRRT Continuous renal replacement therapy

Approximately $80 \%$ of an inhaled dose is deposited onto the upper respiratory tract lining and $13 \%$ in the bronchi and lungs where it exerts its antiviral effect. Ten per cent to $20 \%$ of inhaled drug is absorbed and eliminated unchanged into the urine. Because inhaled zanamivir may induce bronchospasm, the Canadian product monograph advises against its use in persons with severe asthma or chronic obstructive pulmonary disease. No dose reductions are recommended for any patient population.

There have been case reports of mechanically ventilated patients with $\mathrm{A}(\mathrm{H} 1 \mathrm{~N} 1)$ pdm09 influenza who had been treated with zanamivir diskhaler powder in water, administered by nebulizer resulting in bronchospasm and obstruction of ventilator filters (36).

Intravenous formulations of zanamivir are under clinical investigation but are not authorized for use in Canada. In specific circumstances, intravenous zanamivir may be obtained through the Special Access Programme of Health Canada (www.hc-sc.gc.ca/dhp-mps/ acces/drugs-drogues/index-eng.php).

Combination therapy: The clinical utility of combination therapy for treating influenza remains uncertain. A retrospective cohort study compared a triple combination of drugs (oseltamivir, amantadine and ribavirin) and oral oseltamivir in adults with serious influenza illness requiring ventilator support (37). Both regimens were similarly effective in reducing mortality. A modelling study using three antiviral drugs with different mechanisms of action suggested that this therapeutic strategy could delay the emergence of resistance better than treatment with a single influenza inhibitor (38).

\section{Benefits of antiviral treatment}

NAI therapy of patients ill with infection due to seasonal influenza viruses has been demonstrated in controlled trials to reduce the duration and severity of uncomplicated, self-limited, laboratory-confirmed influenza, largely due to influenza A viruses, in otherwise healthy children older than one year of age and adults $(39,40)$.

A meta-analysis concluded that these drugs appeared to reduce total influenza-related complications but could not distinguish between mild and serious complications (41). NAIs have been shown to reduce the frequency of otitis media as a complication of influenza in pediatric patients (40). NAI treatment of hospitalized patients with seasonal influenza may reduce the duration of hospitalization and mortality (42).

In a number of observational studies of patients with $\mathrm{A}(\mathrm{H} 1 \mathrm{~N} 1)$ pdm09 infection, it was reported that treatment with NAIs, chiefly oseltamivir, reduced the progression and severity of illness in the general population as well as in vulnerable groups. These groups include pregnant women and solid organ transplant recipients (43).

As noted above, in vitro and available clinical data from observational studies (20-22), but not randomized controlled trials, suggest that inhaled zanamivir may be more efficacious than oral oseltamivir for the treatment of influenza B virus infection in older, but not younger, children.

Investigational intravenous zanamivir $600 \mathrm{mg}$ twice daily has been reported to be efficacious in preventing experimental human influenza A virus infection (44), treating oseltamivir-resistant $\mathrm{A}(\mathrm{H} 1 \mathrm{~N} 1)$ pdm09 pneumonitis $(45,46)$ as well as for treatment of critically ill patients with $\mathrm{A}(\mathrm{H} 1 \mathrm{~N} 1)$ pdm09 influenza (47). Based on these data, intravenous zanamivir is recommended for antiviral therapy of patients severely ill with suspected or confirmed oseltamivir-resistant influenza who are unable to use the inhalational device.

Inasmuch that a number of respiratory tract viral pathogens can cause an influenza-like illness, anti-influenza drug therapy will invariably result in treatment of some persons whose influenza-like illness is not due to influenza virus per se. At present, there are no data to suggest that such treatment is ecologically harmful. Because NAIs are specific inhibitors of only influenza virus neuraminidase, such treatments are unlikely to engender resistance in other microorganisms. Moreover, influenza viruses are not constituents of the normal flora of humans.

\section{Considerations in selecting treatments}

The indications for treatment may be structured around the following considerations: severity of illness; presence of risk factors or comorbid conditions; interval between onset of illness and diagnosis; and likely influenza type(s) causing infection (see previous section 'The Disease').

Severity of illness: Useful definitions of the range of clinical illness caused by influenza viruses have been adapted from those published by the Centers for Disease Control and Prevention (48):

- Mild or uncomplicated illness is characterized by typical symptoms such as fever (although not everyone with influenza, especially at the extremes of age, will experience a fever), cough, sore throat, rhinorrhea, muscle pain, headache, chills, malaise, sometimes diarrhea and vomiting, but no shortness of breath and little change in chronic health conditions.

- Moderate or progressive illness is characterized by typical symptoms plus signs or symptoms suggesting more than mild illness: chest pain, poor oxygenation (eg, tachypnea, hypoxia, laboured breathing), cardiopulmonary insufficiency (eg, low blood pressure), central nervous system impairment (eg, confusion, altered mental status), severe dehydration or exacerbations of chronic conditions (eg, asthma, chronic obstructive pulmonary disease, chronic renal failure, diabetes or cardiovascular disease).

- Severe or complicated illness is characterized by signs of lower respiratory tract disease (eg, hypoxia requiring supplemental oxygen, abnormal chest radiograph, mechanical ventilation), central nervous system abnormalities (encephalitis, 
encephalopathy), complications of low blood pressure (shock, organ failure), myocarditis or rhabdomyolysis, or invasive secondary bacterial infection based on laboratory testing or clinical signs (eg, persistent high fever and other symptoms beyond three days).

Presence of risk factors or comorbid medical conditions:

- Patients with risk factors such as age, ethnicity or comorbid medical conditions have been identified as being at greater risk for complications of influenza based on extensive experience during seasonal influenza outbreaks and recent experience during the A(H1N1)pdm09 pandemic (Table 4).

Notwithstanding the above association of the aforementioned medical conditions as risk factors for severe influenza, 20\% to $40 \%$ of patients with severe $\mathrm{A}(\mathrm{H} 1 \mathrm{N1}) \mathrm{pdm} 09$ influenza admitted to intensive care units were previously healthy persons not belonging to any known high-risk group. The corollary is that practitioners must be vigilant in their evaluation of otherwise healthy individuals in whom seasonal influenza illness appears to be mild but may be progressing.

Interval between onset of illness and initiation of antiviral therapy: Initiation of treatment of uncomplicated seasonal influenza in healthy adults and children with NAI within $36 \mathrm{~h}$ to $48 \mathrm{~h}$ of illness onset is efficacious. Optimal benefits are obtained if treatment is initiated as early as possible after the onset of symptoms (49). Thus, initiating treatment within $12 \mathrm{~h}$ of illness onset should be a practice goal.

Likely influenza type(s) causing infection: As discussed in the previous section 'The Disease', it is uncertain what will be the predominant strain of influenza causing illness in the 2012/2013 influenza season. Practitioners should be mindful of reports in the Public Health Agency of Canada's FluWatch and reports from their provincial or territorial public health departments. This may be important in case oseltamivirresistant seasonal influenza viruses reappear.

\section{Treatment of children}

While some aspects of influenza prevention and treatment in adults can be extrapolated to children, there are several areas where special pediatric considerations are necessary. In general, when compared with adults, there are fewer data to guide the management of children, notably young infants.

The incidence of seasonal influenza in healthy children is generally $10 \%$ to $40 \%$ each year, but rates as low as $3 \%$ have been reported (50). During community outbreaks of seasonal influenza, the highest attack rates occur in school-age children (51). Children are a common source from which infection is spread to other household members. The shedding of virus usually starts $24 \mathrm{~h}$ before the onset of overt symptoms and generally ceases at seven days.

Influenza illness may be indistinguishable from illness due to other respiratory viruses. The atypical and nonspecific nature of influenza illness in young children is evidenced by data that suggest that, among hospitalized children, fever and cough are the most common presenting features (52).

The pulmonary and nonpulmonary influenza-related complications in infants, children and youth are generally similar to those in adults with the exception that some conditions are more likely to be encountered in children (sepsis-like illness, diarrhea, otitis media, severe laryngotracheobronchitis [croup]), febrile seizures, Reye's syndrome and refusal to walk due to myositis (50).

In general, children with pre-existing high-risk medical conditions are more likely to experience adverse outcomes. However, previously healthy children may also experience adverse consequences. In the 2010/2011 influenza virus season in the United States, approximately $50 \%$ of the 115 influenza-related deaths were among previously healthy children (54). Influenza B was identified in a disproportionate number of pediatric influenza-associated deaths (38\%) (53).

Children at the highest risk for adverse outcomes from influenza illness include those younger than five years of age (54). Hospitalizations occur more frequently among those younger than two years of age compared with older children, with the highest hospitalization rates being among those younger than six months of age (52). This does not necessarily translate into a decision to uniformly use antiviral therapy in those younger than two years of age; such children with mild influenza illness do not usually need treatment.

Among the currently available antiviral agents, three are approved for use for children in Canada: amantadine (which is not currently useful because of resistance) for influenza A; and oseltamivir and zanamivir for influenza A and B. Clinical trials supporting the role of the NAIs in children were previously summarized and have been the subject of recent meta-analyses $(40,55)$. One meta-analysis $(55)$ suggested that the NAIs shorten the duration of illness in children with seasonal influenza and reduce household transmission, but that they have little effect on asthma exacerbations or the use of antibiotics.

Indeed, data from the only double-blind, randomized, controlled trial on oseltamivir for the treatment of influenza in previously healthy children indicated significant reductions in physician-diagnosed complications requiring antibiotic therapy (relative risk reduction 40\%), and in the likelihood of developing otitis media (relative risk reduction 44\%) (56). Another randomized trial among children aged one to three years indicated an $85 \%$ reduction in acute otitis media when oseltamivir was started within $12 \mathrm{~h}$ after the onset of influenza illness, but no reduction when treatment was started at $>24 \mathrm{~h}$ after the onset of symptoms (57). A benefit on asthma exacerbations among oseltamivir-treated children has also been demonstrated in a randomized controlled trial (58).

Since the earlier studies on NAIs, additional studies have been reported and are in progress and experience with their use has increased (59-62). However, there exists a relative paucity of new data from randomized trials involving infants and young children. Recent studies have provided valuable safety data (63) as well as data on the use of oseltamivir in premature newborns (64). However, its use for 2012/2013 seasonal influenza in infants should be handled on a caseby-case basis, based on severity of illness, because it is not approved for this indication in Canada. Oseltamivir was temporarily approved for use in infants younger than one year of age on the basis of a favourable risk-to-benefit ratio during the $2009 \mathrm{H} 1 \mathrm{~N} 1$ pandemic. Recommendations for oseltamivir dosing for infants younger than one year of age varied within a reasonably narrow range and have been updated for seasonal influenza (65-67). Current dosing recommendations are shown in Table 5.

\section{Treatment of immunocompromised patients}

This group includes individuals with a wide range of congenital and acquired immunodeficiencies. The heterogeneity of populations of immunocompromised hosts is well recognized, resulting in varying degrees of risk for adverse outcomes from influenza illness. In this context, Table 7 summarizes selected clinical, laboratory and other markers that help to categorize various immunodeficiency states and identify patients who might be at the greatest risk of adverse outcomes from influenza illness (68). The presence of these markers suggest increased risk for acquisition of infection, progression to more severe and potentially life-threatening consequences of infection, and for an impaired ability to develop immunity to infection following subsequent exposure to influenza virus (68).

In addition to the well-recognized variability in the clinical manifestations of influenza illness, atypical clinical features may be present in immunocompromised individuals. For example, immunocompromised individuals may present with fever as the sole manifestation of influenza illness (69) and may present with respiratory symptoms without fever (70).

The complications seen among persons with normal immune systems may also be seen in immunocompromised hosts. Invasive secondary bacterial infections caused by $S$ pneumoniae, $S$ aureus, Streptococcus pyogenes and other bacterial pathogens may occur and can be devastating for the immunocompromised host. For example, asplenic individuals are known to be at increased risk of severe invasive pneumococcal disease. 


\begin{tabular}{|c|c|c|}
\hline $\begin{array}{l}\text { Laboratory-based indices } \\
\text { (significant risk) }\end{array}$ & $\begin{array}{l}\text { Clinical states (significant but variable risk due to } \\
\text { heterogeneity in clinical states) }\end{array}$ & $\begin{array}{l}\text { Treatment-related indices (significant but variable } \\
\text { risk due to heterogeneity in nature and intensity of } \\
\text { treatments) }\end{array}$ \\
\hline $\begin{array}{l}\text { Severe neutropenia } \\
\left(\text { ANC }<0.5 \times 10^{9} / \mathrm{L}\right) \\
\text { AND/OR } \\
\text { severe lymphopenia } \\
\left(\text { ALC }<0.5 \times 10^{9} / \mathrm{L}\right)\end{array}$ & $\begin{array}{l}\text { Individuals with malignancies receiving active cytotoxic } \\
\text { chemotherapy } \\
\text { Acute leukemia patients } \\
\text { HSCT recipients } \\
\text { Solid organ transplant recipients (eg, lung, heart, kidney) } \\
\text { Individuals with congenital immunodeficiency states } \\
\text { Individuals with acquired immunodeficiency states (eg, HIV } \\
\text { infection, plasma cell dyscrasias, B-lymphocyte malignancies) } \\
\text { Individuals with rheumatic diseases or autoimmune disorders } \\
\text { (eg, rheumatoid arthritis or systemic lupus erythematosis) } \\
\text { Individuals with gastrointestinal diseases receiving } \\
\text { immunosuppressive drugs (eg, inflammatory bowel disease) } \\
\text { Individuals on renal dialysis } \\
\text { Individuals with asthma or COPD receiving corticosteroid therapy }\end{array}$ & $\begin{array}{l}\text { A history of ongoing myelosuppressive and/or } \\
\text { immunosuppressive therapies such as: } \\
\text { - Corticosteroid therapy (71) (ie, among adult patients } \\
>700 \mathrm{mg} \text { cumulative dose of prednisone equivalent on } \\
\text { an ongoing basis and at the time of clinical evaluation; } \\
\text { among pediatric patients }(72)>2 \mathrm{mg} / \mathrm{kg} \text { per day of } \\
\text { prednisone or its equivalent, or }>20 \mathrm{mg} / \text { day if they } \\
\text { weigh more than } 10 \mathrm{~kg} \text { administered for } 14 \text { days or } \\
\text { more); } \\
\text { - Cytotoxic therapy*; } \\
\text { - Immunomodulator therapies }{ }^{\dagger}\end{array}$ \\
\hline
\end{tabular}

Adapted from reference 69. *Examples of cytotoxic therapy include, but are not limited to: anthracyclines such as doxorubicin or epirubicin; purine analogues such as azathiaprine, thioguanine, mercaptopurine, fludarabine, pentostatin, or cladribine; pyrimidine analogues such as flurorouracil, cytarabine, capecitabine, or gemcitabine; antifolate agents such as methotrexate or premetrexed; alkylating agents such as the nitrogen mustards (cyclophosphamide or ifosphamide), nitrosoureas (carmustine, lomustine, semustine, streptozotocin) and platinum analogues (cis-platin, carboplatin, or oxaliplatin); taxanes (eg, docetaxel, paclitaxel); topoisomerase I inhibitors (eg, irinotecan); ' Examples of immunomodulator therapy include, but are not limited to: calcineurin inhibitors (eg, cyclosporine, tacrolimus, sirolimus), guanine synthesis inhibitors (eg, mycophenolate mofetil), anti-B lymphocyte therapy (eg, rituximab), anti-T lymphocyte therapy (eg, antithymocyte globulin or antiCD3), anti-B and $T$ cell therapy (eg, alemtuzumab, basiliximab, daclizumab), Anti-tissue necrosis factor therapy (eg, infliximab or etanercept), aAlpha-interferon therapy. ALC Absolute lymphocyte count; ANC Absolute neutrophil count; COPD Chronic obstructive pulmonary disease; HSCT Hematopoietic stem cell transplant

Prolonged illness and viral shedding are features of infection in immunocompromised individuals. Indeed, in some of the more immunocompromised individuals, the virus may be persistently present in the respiratory tract for several weeks or months $(71,72)$. This persistent shedding may be accompanied by periodic exacerbations of illness $(71,72)$. Cell-mediated immunity is important in mediating protection from influenza illness, viral clearance and recovery from illness $(72-76)$. Thus, reductions in $\mathrm{T}$ cell number or function as a result of acquired or congenital immunodeficiency states may result in an increased likelihood of a more severe and prolonged illness and an increased risk of antiviral resistance $(72,73)$. The risk for immunocompromised persons is compounded if they are in comorbid states that are themselves risk factors for adverse outcomes from influenza illness (eg, underlying chronic lung disease). The risk among these individuals may be variable due to several factors, including differences in the nature of their immunosuppressive therapies $(77,78)$.

The importance of early treatment of influenza illness in immunocompromised hosts (eg, organ transplant recipients) is well documented. Protracted illness and virus shedding may prompt physicians to prolong antiviral therapy with oseltamivir. However, the likelihood of antiviral resistance is a major concern with prolonged oseltamivir therapy of immunocompromised patients (79). Accordingly, practitioners should consult with experts and monitor for antiviral resistance when treating such patients.

\section{Treatment of patients with renal impairment}

Recommended oseltamivir regimens for treatment and prophylaxis of patients with renal impairment or failure are presented in Table 6 $(26,27,28)$. No dosage adjustments are required for inhaled zanamivir treatment in patients with renal impairment.

\section{Treatment of pregnant patients}

During seasonal influenza epidemics, healthy pregnant women with influenza, especially those in the third trimester of pregnancy, experienced rates of hospitalization in excess of those observed in age-matched nonpregnant women with influenza (80). Moreover, the rates of hospitalization were comparable with those observed in individuals with other recognized comorbid conditions that increase the risk of influenza-related complications (80). As a result of such data, pregnancy is now recognized to be a risk factor that warrants annual influenza immunization. During the 2009 A(H1N1)pdm09 pandemic, not only were increased rates of hospitalization again observed in healthy pregnant women, most of whom were in the second and third trimester, but increased rates of death were also observed compared with nonpregnant women (81). Such excess mortality had previously been observed during the 1918 and 1957 pandemics. New evidence indicates that there is a significant increase in stillbirths, premature deliveries and infant mortality when women contract influenza in the third trimester (82).

Oseltamivir pharmacokinetics in pregnant women with influenza are not different from one trimester to another (83). Oseltamivir is excreted in breast milk, but at concentrations below that required to inhibit current influenza A and B strains (84). These observations taken together support the recommendation to treat influenza in pregnant women in all trimesters with oseltamivir in standard doses as soon as possible after the onset of influenza-like symptoms (85).

Oseltamivir and zanamivir are listed by the United States Food and Drug Administration as pregnancy category $\mathrm{C}$ drugs, reflecting the fact that no clinical studies have been performed to assess their safety during pregnancy. No adverse effects on the woman or fetus have been observed as a result of treatment with oseltamivir during pregnancy $(86,87)$

Some authorities recommend oseltamivir in preference to zanamivir during pregnancy because it is systemically absorbed (88). Systemically absorbed oseltamivir would likely be delivered to virusinfected respiratory tract tissues more consistently than would inhaled zanamivir, especially in the later stages of pregnancy when diaphragmatic excursion, limited by the gravid uterus, may impair necessary distribution of inhaled zanamivir through the respiratory tract. Oseltamivir is now recommended for the treatment of influenza in pregnant women. 


\section{RECOMMENDATIONS FOR TREATMENT}

General principles

- Treatment should be initiated as rapidly as possible after onset of illness because the benefits of treatment are much greater with initiation at $<12 \mathrm{~h}$ than at $48 \mathrm{~h}$. (Strong recommendation, Grade B evidence)

- Antiviral therapy should be initiated even if the interval between illness onset and administration of antiviral medication exceeds $48 \mathrm{~h}$ if:

i. The illness is severe enough to require hospitalization (Strong recommendation, Grade X evidence);

ii. The illness is progressive, severe or complicated, regardless of previous health status (Strong recommendation, Grade X evidence); or

iii. The individual belongs to a group at high risk for severe disease (Strong recommendation, Grade X evidence).

- Otherwise healthy patients with relatively mild, self-limited influenza are not likely to benefit from NAI therapy initiated more than $48 \mathrm{~h}$ after illness onset. Clinical judgment should be used. (Option, Grade D evidence)

- Patients for whom antiviral therapy is not recommended should be advised of symptoms and signs of worsening illness that might warrant reassessment. (Recommendation, Grade D evidence)

- Treatment duration should routinely be five days (Strong recommendation, Grade A evidence), but may be continued longer than five days if clinically indicated. (Option, Grade D evidence)

- Intubated patients with influenza illness should receive oseltamivir through a nasogastric tube. (Recommendation, Grade C evidence)

- For patients unable to tolerate or receive oral oseltamivir, inhaled or intravenous zanamivir is a suitable option. (Option, Grade D evidence)

- Zanamivir may be preferred to oseltamivir in the following situations:

i. Patients not responding to oseltamivir therapy (Recommendation, Grade C evidence); or

ii. Patients with illness despite oseltamivir prophylaxis (Recommendation, Grade C evidence).

- For severely ill patients, zanamivir administered intravenously is preferred to inhaled drug. (Recommendation, Grade D evidence)

- In ventilated patients, zanamivir should only be administered intravenously (Strong recommendation, Grade X evidence)

- If patients are not responding to oseltamivir therapy, their virus should be tested for oseltamivir resistance (Option, Grade D evidence)

Treatment of nonpregnant adults with mild or uncomplicated influenza illness

A treatment algorithm is provided as Appendix A.

- For individuals with mild disease, no risk factors and:

i. illness of less than $48 \mathrm{~h}$ duration, treatment with oseltamivir or inhaled zanamivir may be considered. (Option, Grade A evidence)

ii. illness of more than $48 \mathrm{~h}$ duration, antiviral treatment is not recommended. (Recommendation, Grade C evidence)

- For individuals with mild disease, risk factors and:

i. illness of less than $48 \mathrm{~h}$ duration, treat with oseltamivir or inhaled zanamivir. (Strong recommendation, Grade X evidence)

ii. illness of more than $48 \mathrm{~h}$ duration, treatment with oseltamivir or inhaled zanamivir may be considered. (Option, Grade D evidence)
Treatment of nonpregnant adults with moderate, progressive, severe or complicated influenza illness with or without risk factors A treatment algorithm is provided as Appendix B.

- Consider hospitalization and admission to the intensive care unit. (Recommendation, Grade C evidence)

- Oseltamivir $75 \mathrm{mg}$ every $12 \mathrm{~h}$ orally or by nasogastric tube should be started immediately. (Recommendation, Grade C evidence)

- Oseltamivir should be started even though the window between symptom onset and initial administration of antiviral is longer than 48 h. (Recommendation, Grade C evidence)

- Treatment with zanamivir instead of oseltamivir should be considered for:

i. Those not responding to oseltamivir therapy, (Recommendation, Grade C evidence); or

ii. Those with illness despite oseltamivir prophylaxis, (Recommendation, Grade C evidence)

ii. Those with significant immunosupression. (Option, Grade D evidence).

Treatment of infants, children and youth with mild or uncomplicated influenza illness

A treatment algorithm is provided as Appendix C.

- For those with mild disease and no risk factors other than age:

i. Younger than one year of age: NAIs are currently not approved for the routine treatment of seasonal influenza illness. Given that infants younger than six months of age are not eligible for influenza vaccination, immunization of their household and other close contacts is important in protecting them against influenza, thereby potentially leading to reduced need for antiviral therapy. Influenza immunization of the pregnant woman may also provide protection to the infant during the first six months of life. (Option, Grade D evidence)

ii. One to less than five years of age: although children under five years of age are classified as high risk (with those younger than two years of age having the highest risk), those who are otherwise healthy and have mild disease not requiring hospitalization do not routinely require antiviral therapy. For these children, treatment is optional. (Option, Grade D evidence).

iii. Five or more years of age: antiviral therapy is not routinely recommended for children and youth who are otherwise healthy and have mild disease not requiring hospitalization. (Option, Grade D evidence)

- For those with mild disease and risk factors other than age:

i. Younger than one year of age: NAIs are currently not approved for the routine treatment of seasonal influenza illness.

ii. One or more years of age: illness of less than $48 \mathrm{~h}$ duration, treat with oseltamivir or if age appropriate, inhaled zanamivir (Recommendation, Grade B evidence)

iii. One or more years of age: illness of more than $48 \mathrm{~h}$ duration, treatment with oseltamivir or if age appropriate, inhaled zanamivir may be considered on a case-by-case basis. (Option, Grade D evidence)

Treatment of infants, children and youth with moderate, progressive, severe or complicated influenza illness with or without risk factors:

- Consider hospitalization and admission to the intensive care unit. (Recommendation, Grade C evidence)

- Start treatment immediately (Strong recommendation, Grade B evidence)

- Treat with oseltamivir or zanamivir in appropriate doses (Table 5)

- Oseltamivir or zanamivir should be started even though the window 
between symptom onset and initial administration of antiviral is longer than $48 \mathrm{~h}$. (Recommendation, Grade C evidence)

- Treatment with zanamivir instead of oseltamivir should be considered for:

i. Those not responding to oseltamivir therapy (Recommendation, Grade C evidence)

ii. Those with illness despite oseltamivir prophylaxis (Recommendation, Grade C evidence)

- Although oseltamivir was approved temporarily for use in infants younger than one year of age on the basis of a favourable risk-tobenefit ratio during the recent $2009 \mathrm{H} 1 \mathrm{~N} 1$ pandemic, its use in this population for seasonal influenza should be handled on a case-by-case basis, based on severity of illness. (Option, Grade D evidence)

Treatment of immunocompromised patients

Recommendations

1. Immunocompromised individuals who have uncomplicated influenza illness are at risk of developing severe or complicated illness and thus should be treated with oseltamivir as soon as possible without regard to the duration of illness. (Recommendation, Grade C evidence)

2. Immunocompromised patients should be treated with zanamivir if they have recently received or are currently receiving oseltamivir as prophylaxis or therapy. (Option, Grade D evidence)

3. Prolonged antiviral therapy should be avoided in immunocompromised individuals, if possible, due to the potential for antiviral resistance. (Option, Grade D evidence)

4. Early initiation of therapy for symptomatic infection in immunocompromised patients is preferred over PEP. In the setting of a defined, significant exposure (eg, household contact or health care-associated exposure such as shared hospital accommodation) of an immunocompromised patient to a proven or suspect case of influenza, PEP may be considered. (Option, Grade D evidence)

5. In exposed, susceptible, profoundly immunosuppressed individuals at very high risk of complications, presumptive treatment may be initiated before the onset of symptomatic illness. (Option, Grade D evidence)

6. For early presumptive treatment, oseltamivir is preferred. (Option, Grade D evidence)

\section{Treatment of patients with renal impairment}

See the relevant sections above and Table 6 for treatment recommendations of adults and children with renal impairment as a risk factor.

\section{Treatment of pregnant women}

Oseltamivir in standard doses is recommended for treatment of pregnant women with influenza based on the extensive safe use of oseltamivir to treat pregnant women during the 2009 H1N1 pandemic. (Strong recommendation, Grade C evidence)

\section{CHEMOPROPHYLAXIS VERSUS EARLY THERAPY}

Antiviral prophylaxis with NAIs has been demonstrated to be efficacious and well tolerated. Three chemoprophylactic strategies were detailed in the previous guideline (1): seasonal prophylaxis; PEP or contact exposure; and outbreak control. Antiviral chemoprophylaxis is recommended only in very selected circumstances:

- Seasonal prophylaxis involves continuous (usually daily) administration of antiviral medication for all or part of an influenza season to prevent influenza illness. This may include circumstances in which effective vaccine is not available or vaccine is contraindicated. Although efficacious in the setting of clinical trials, the practicality and effectiveness of such seasonal prophylaxis in the field have not been established. Two weeks of prophylaxis initiated at the time of administration of injected, inactivated influenza vaccine during the influenza season may be considered to prevent influenza until vaccine-induced immunity develops, a strategy referred to as bridging prophylaxis.

- $\mathrm{PEP}$ is an efficacious strategy when initiated in the first $48 \mathrm{~h}$ after exposure to an infectious ill contact. Contacts are considered infectious for the interval beginning $24 \mathrm{~h}$ before illness onset until the time fever ends. However, it is recommended that the strategy of early treatment be used in place of PEP because of reports of oseltamivir resistance arising during PEP. Early presumptive therapy may be appropriate for situations in which influenza infection appears prevalent and persons at very high risk of influenza complications are exposed (65). Early presumptive treatment requires initiation of therapy with oseltamivir or zanamivir twice daily (versus once daily as recommended for PEP) initiated after exposure to an infectious contact even before symptoms begin.

- Outbreak control: chemoprophylaxis combined with antiviral treatment of ill persons plus other measures is recommended for controlling outbreaks of influenza in closed facilities. Closed facilities have a fixed residential population with limited turnover or units that can be closed (89). Closed facilities include nursing homes and other long-term care facilities that house patients at high risk of influenza complications (89) as well as correctional institutions that pose special other risks and considerations with respect to influenza outbreaks due to their unique environment; these factors mandate consideration of the same measures for outbreak management in both (90). Chief among these additional measures is the concurrent administration of inactivated influenza vaccine parenterally. Zanamivir does not interfere with the hemagglutination antibody response to injected vaccine (91). A similar lack of interference with oseltamivir would be expected. Nasal attenuated live influenza vaccine (Flumist, Astra Zeneca Canada Inc, USA) should not be used in these situations, because oseltamivir and zanamivir would be expected to interfere with its immunogenicity.

\section{Recommendations for antiviral prophylaxis}

- Early therapy is preferred over routine seasonal pre-exposure prophylaxis (Recommendation, Grade D evidence).

- An early treatment strategy should involve counselling together with arrangements for contacts to have medication on hand. (Option, Grade D evidence)

- Some experts recommend the selective use of pre-exposure prophylaxis for the following scenarios (Option, Grade D evidence) during community outbreaks of influenza illness:

i. As a bridge to vaccine-induced immunity during the 14-day period after immunization of high-risk individuals;

ii. Protection of high-risk persons for whom vaccination is contraindicated or deemed likely to be ineffective;

iii. Protection of patients at high risk and their family members and close contacts when circulating strains of influenza virus in the community are not matched with trivalent seasonal influenza vaccine strains, based on current data from the local or national public health laboratories;

iv. Protection of family members or health care workers for whom influenza immunization is contraindicated (eg, known anaphylaxis to chicken or egg protein) (92) and who are likely to have ongoing close exposure to unimmunized persons at high risk including infants and toddlers who are younger than 24 months of age (www.cps.ca/english/statements/ID/ ID11-06.htm).

- Early therapy is preferred over PEP due to concerns regarding drug resistance. (Option, Grade D evidence)

An algorithm for prophylaxis is provided as Appendix D.

- PEP may be considered in family settings for persons who cannot be reliably protected by immunization (eg, younger than six months of age, immunocompromised or vaccine contraindicated). (Option, Grade D evidence) 
- To control outbreaks in closed facilities, antiviral drug prophylaxis, combined with treatment and inactivated vaccine administration, is indicated. (Strong recommendation, Grade C evidence)

- Neither early treatment nor PEP should be prescribed:

i. For groups of healthy individuals based on possible exposure in the community

ii. If the close contact did not occur during the infectious period of the person with suspected or confirmed influenza (from one day before the onset of symptoms until $24 \mathrm{~h}$ after fever ends)

iii. If more than four days have elapsed since the last infectious contact (Option, Grade D evidence)

ACKNOWLEDGEMENTS: We acknowledge the critical review of the present document by the Public Health Agency of Canada and the Infectious Diseases and Immunization Committee of the Canadian Paediatric Society and its review and endorsement by the AMMI Canada Guidelines Committee. The authors also extend appreciation to Ms Angela Nelson for her excellent secretarial assistance.

CONFLICT OF INTEREST DECLARATION: Dr Fred Y Aoki:

Honoraria: Hoffmann La Roche Inc, GlaxoSmithKline and Merck; Advisory Board: GlaxoSmithKline, Hoffmann La Roche Inc; Research: GlaxoSmithKline, Hoffmann La Roche Inc, Biocryst Inc, Merck. Dr Upton D Allen: Research: Hoffmann La Roche Inc. Dr H Grant Stiver: Honoraria: Hoffman La Roche Inc; Advisory Board: Hoffman La Roche Inc. Dr Gerald A Evans: Research: Biocryst Inc. 
APPENDIX A

Algorithm for oseltamivir and zanamivir treatment of mild or uncomplicated influenza in adults - October 2012

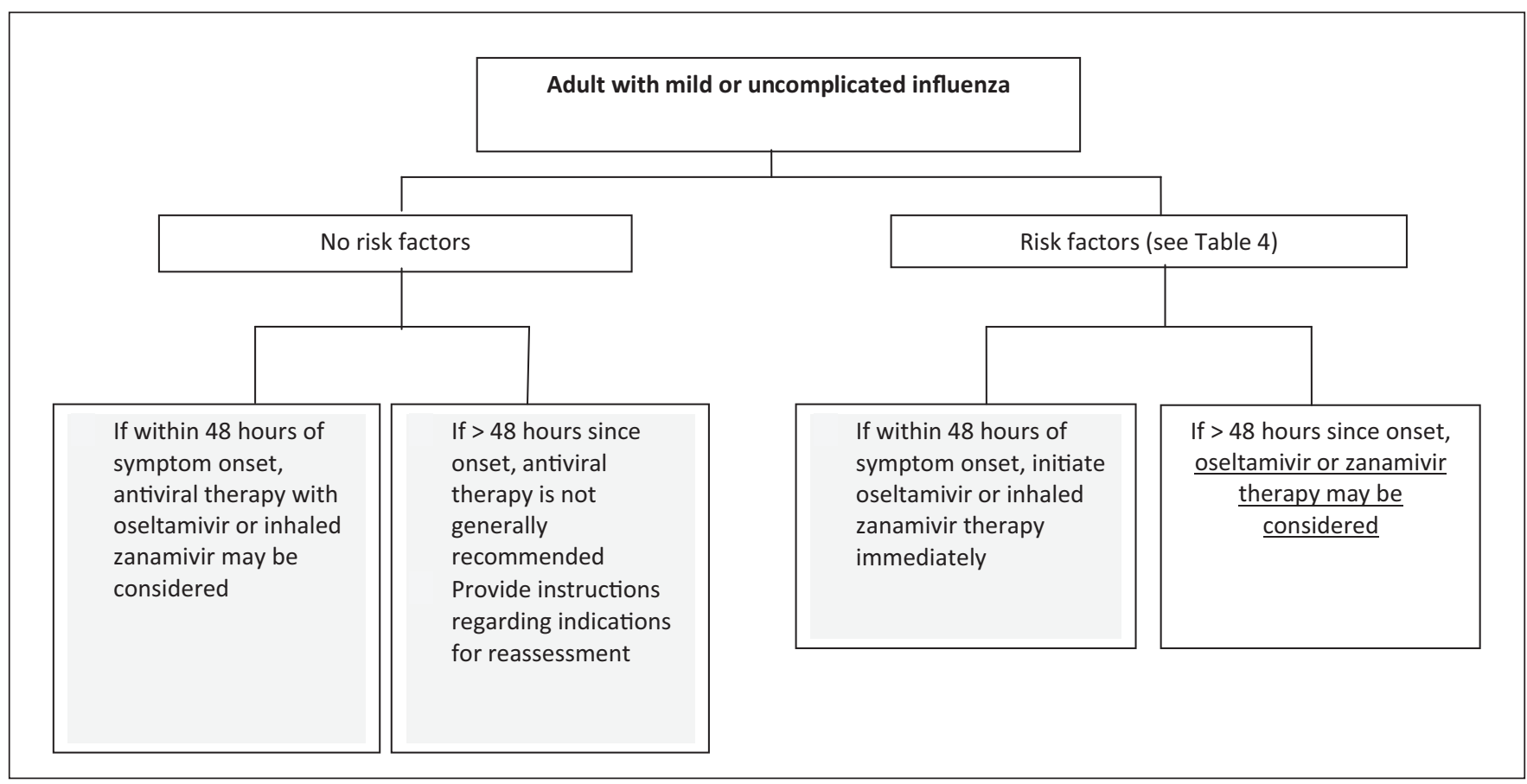

\section{APPENDIX B}

Algorithm for oseltamivir and zanamivir treatment of moderate, progressive, severe or complicated influenza in adults - October 2012 (BID Twice daily)

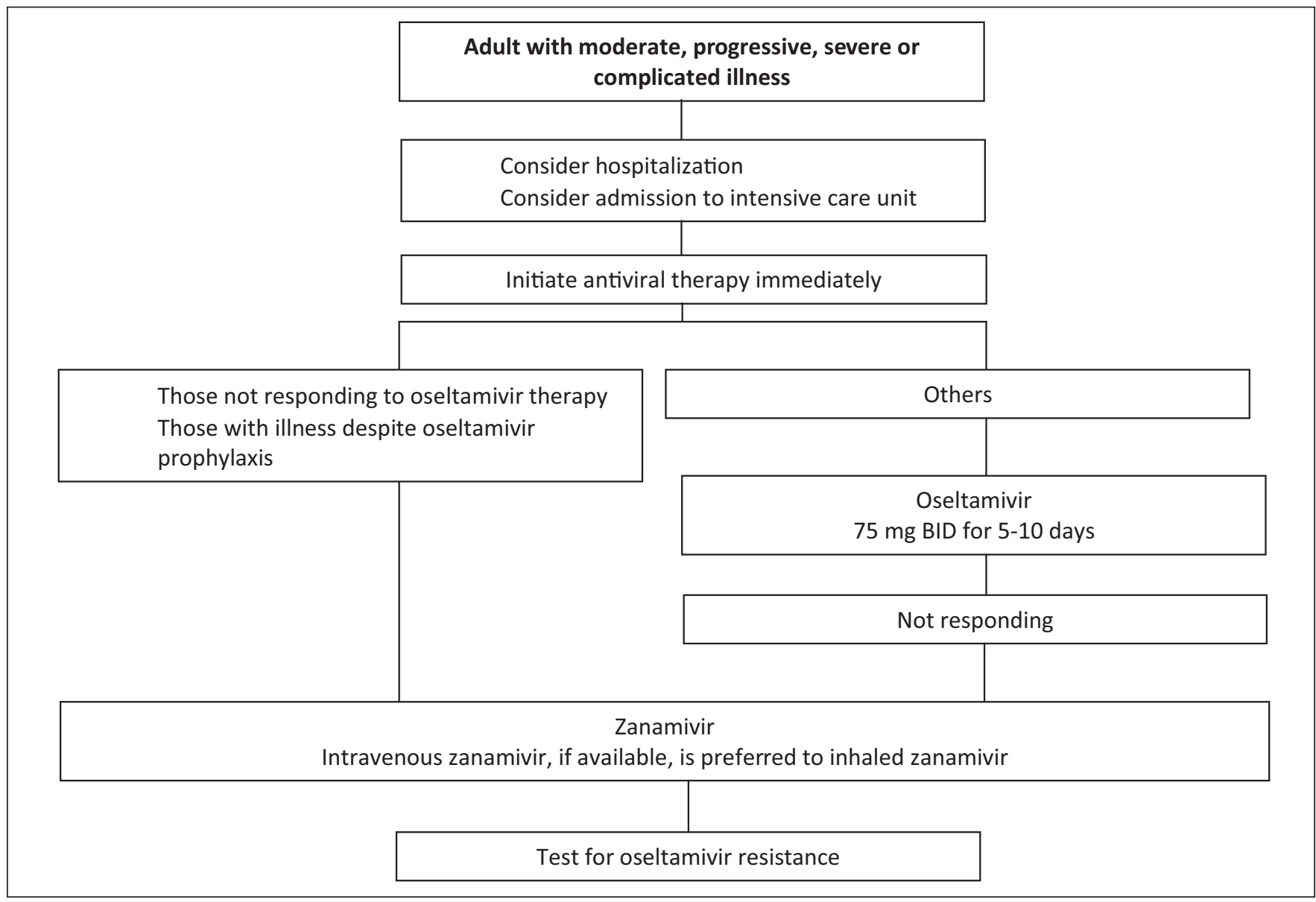




\section{APPENDIX C}

Algorithm for oseltamivir and zanamivir treatment of influenza in children and youth $(<18$ years old) - October 2012

*In those with mild or uncomplicated illness antiviral treatment is not routinely recommended and should not be used if symptoms have been present for more than $48 \mathrm{~h}$.

**Treatment with oseltamivir or if age appropriate, inhaled zanamivir may be considered on a case-by-case basis even if symptoms have been present for more than $48 \mathrm{~h}$. Antivirals are not approved but should be considered in children $<1$ year of age.

(ICU Intesive care unit; IV Intravenous)

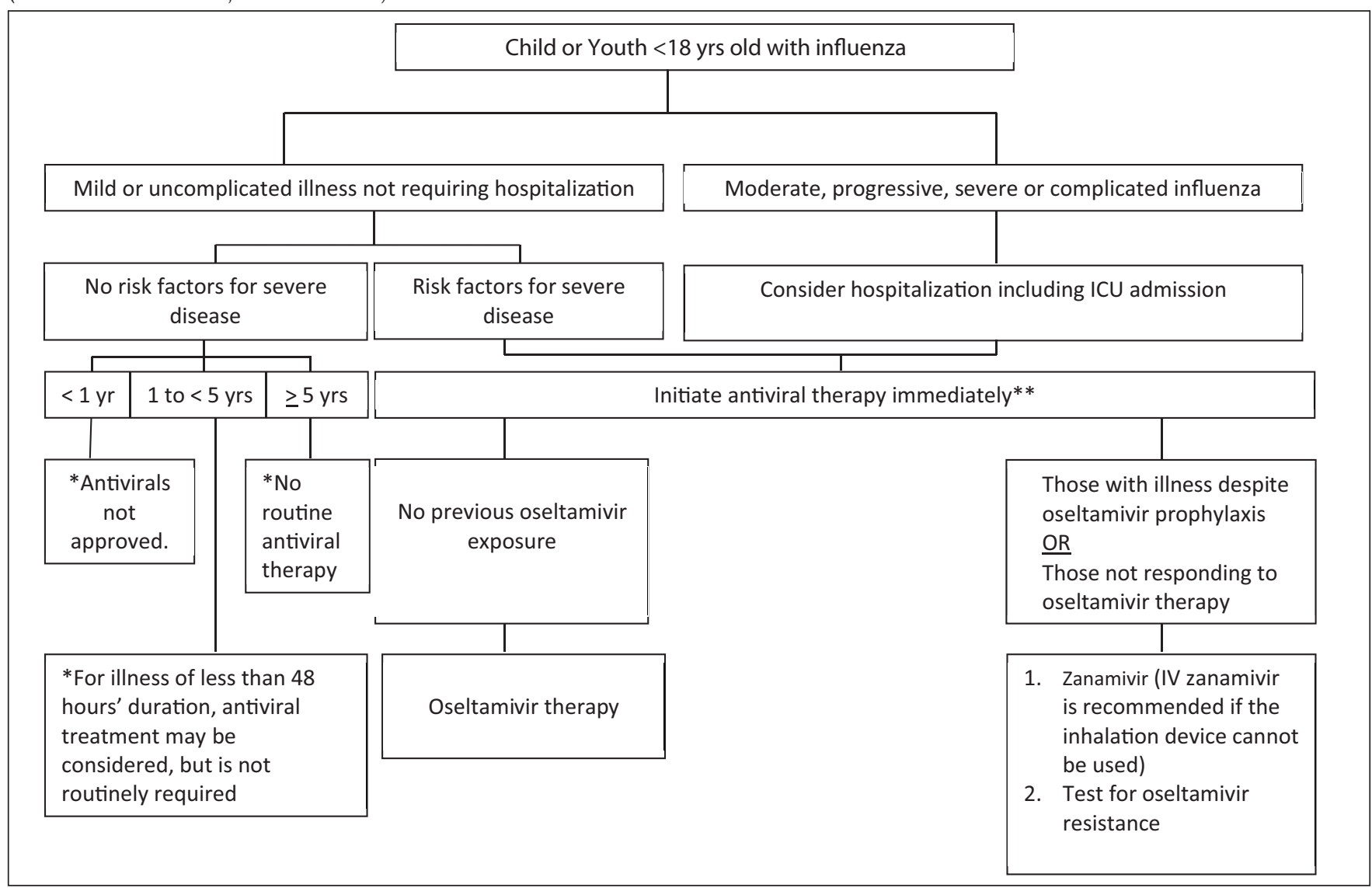

Algorithm for oseltamivir and zanamivir prophylaxis or early treatment in close contacts of infectious patients - October 2012

(*Presumptive treatment is therapy with twice daily doses of oseltamivir or zanamivir initiated before the onset of influenza symptoms in close contacts of individuals with suspected or proven influenza illness)

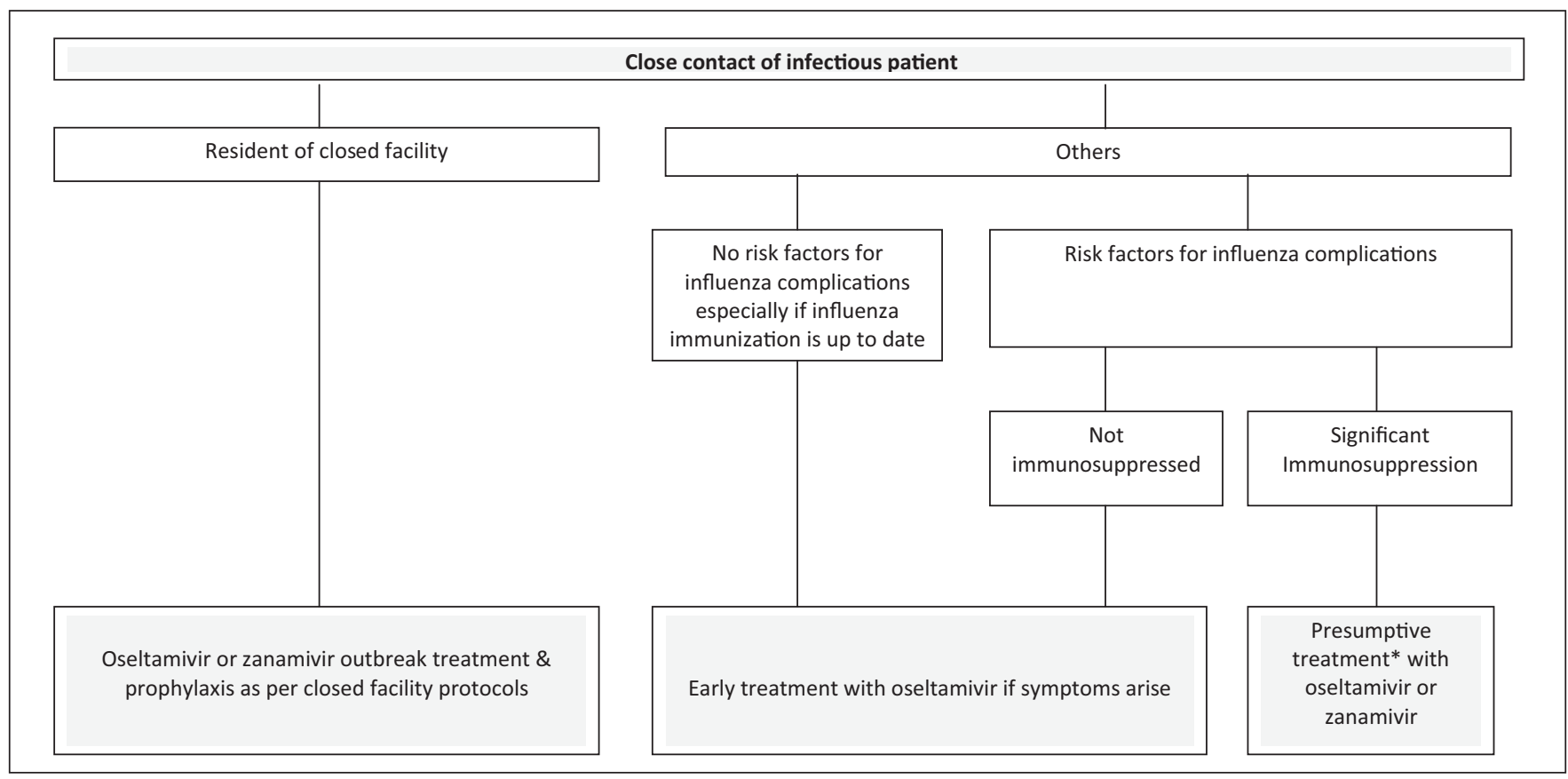




\section{REFERENCES}

1. Aoki FY, Allen UD, Stiver HG, Evans GA. The use of antiviral drugs for influenza: Guidance for practitioners 2011-2012. <www. ammi.ca/guidelines> (Accessed August 2012).

2. American Academy of Pediatrics Steering Committee on Quality Improvement and Management. Classifying recommendations for clinical practice guidelines. Pediatrics 2004:114;874-7.

3. National Advisory Committee on Influenza (NACI). Statement on seasonal influenza vaccine 2012-2013 July 6, 2012 at <http://resources. cpha.ca/immunize.ca/data/1814e.pdf $>$ (Accessed August 2012).

4. Antigenic and genetic characteristics of zoonotic influenza viruses and develpoment of candidate vaccine viruses for pandemic preparedness. Who Wkly Epidemiol Rec No 43. 2011:86:469-80. <http://who.int/wer/2011/wer8643.pdf>. (Accessed August 2012).

5. FluWatch, August 12-25, 2012. Public Health Agency of Canada <http://www.phac-aspc.gc.ca/fluwatch/11-12/w34_12/pdf/fw201234-eng.pdf $>$ (Accessed August 2012).

6. Nguyen-Van-Tam JS. Epidemiology of influenza. In: Nicholson KG, Webster RG, Hay AJ, eds. Textbook of Influenza. Blackwell Science Ltd, Osney Mead, United Kingdom, 1998:181-206.

7. Influenza Antiviral Drug Resistance: Questions \& Answers. Centers for Disease Control and Prevention (CDC) \& national Center for Immunization and Respiratory Diseases (NCIRD), July 23, 2012. <www.cdc.gov/flu/about/qa/antiviralresistance.htm>. (Accessed August 2012).

8. CDC. Seasonal influenza. <www.cdc.gov/flu/about/qa/disease.htm> (Accessed August 2012).

9. CDC. Antiviral agents for the treatment and chemoprophylaxis of influenza. Recommendation of the Advisory Committee on Immunization Practices (ACIP). Morb Mortal Wkly Rep 2011;60:1-25.

10. Clinical Aspects of Pandemic 2009 Influenza A (H1N1) Virus Infection Writing Committee of the WHO Consultation on Clinical Aspects of Pandemic (H1N1) 2009 Influenza. N Engl J Med 2010;362:1708-19.

11. Studahl M. Influenza and CNS manifestations J Clin Virol 2003;28:225-32.

12. National Advisory Committee on Immunization (NACI). Statement on seasonal trivalent inactivated influenza vaccine (TIV) for 2012-2013. <www.phac-aspc.gc.ca/ccdrw-rmtch/indexeng.php $>$ (Accessed August 2012).

13. Blanton L, Peacock G, Cox C, et al. Neurologic disorders among pediatric deaths associated with the 2009 pandemic influenza. Pediatrics 2012:130:390-6.

14. Boivin G, Hardy J, Tellier G, et al. Predicting influenza infections during epidemics with use of a clinical case definition. Clin Infect Dis 2000;31:1166-9.

15. Monto AS, Fleming DM, Henry D, et al. Efficacy and safety of the neuraminidase inhibitor zanamivir in the treatment of influenza A and B virus infections. J Infect Dis 1999; 80:254-61.

16. Nicholson KG, Aoki FY, Osterhaus AD, et al. Efficacy and safety of oseltamivir in the treatment of acute influenza: A randomized controlled trial. Neuraminidase Inhibitor Influenza Treatment Investigator Group. Lancet 2000;355:1845-50.

17. Govaert TM, Dinant GJ, Aretz K, et al. The predictive value of influenza symptomatology in elderly people. Fam Pract 1998;15:16-22.

18. Peltola V, Ziegler T, Ruuskanen O. Influenza A and B virus infections in children. Clin Infect Dis 2003;36:299-305.

19. Aoki FY. Oseltamivir. In: Grayson ML, Crowe SM, McCarthy JS, et al, eds. Kucer's The Use of Antibiotics, 6th edn. London: Edward Arnold Ltd, 2010:3029-42.

20. Kawai N, Ikematsu H, Iwaki N, et al. A comparison of the effectiveness of zanamivir and oseltamivir for the treatment of influenza A and B. J Infection 2008;56:1-7.

21. Sugaya N, Tamara D, Yamazaki M, et al. Comparison of the clinical effectiveness of oseltamivir virus infection in children. Clin Infect Dis 2008;47:339-45.

22. Kawai N, Ikematsu H, Iwaki N, et al. A comparison of the effectiveness of oseltamivir for the treatment of influenza $\mathrm{A}$ and influenza B: A Japanese multicenter study of the 2003-2004 and 2004-2005 influenza seasons. Clin Infect Dis 2006;43:439-44.

23. American Academy of Pediatrics. Antiviral drugs. In: Pickering LR, Baker CJ, Kimberlin DW, Long SS, eds. Red Book 2012 Report of the Committee on Infectious Diseases, 29th edn. Elk Grove Village: American Academy of Pediatrics, 2012:841-7.
24. Thorne-Humphrey LM, Goralski KB, Slayter KC, et al. Oseltamivir pharmacokinetics in morbid obesity (OPTIMO) trial. J Antimicrob Chemother 2011;66:2083-91.

25. Choo D, Hossain M, Liew P, et al. Side effects of oseltamivir in endstage renal failure patients. Nephrol Dialysis Transpl 2011;26:2339-44.

26. Smith JR, Ariano RE, Toovey S. The use of antiviral agents for the management of severe influenza. Crit Care Med 2010;38(4 Suppl):43-51.

27. Robson R, Buttimore A, Lynn K, et al. The pharmacokinetics and tolerability of oseltamivir suspension in patients on haemodialysis and continuous ambulatory peritoneal dialysis. Nephrol Dial Transplant 2006;21:2556-62.

28. Schreuder, MF, van der Flier M, Knops NB, Koster-Kamphuis L, Brüggemann RJ. Oseltamivir dosing in children undergoing hemodialysis. Clin Infect Dis 2010;50:1427-8.

29. Nicholson KG. Human influenza. In: Nicholson KG, Webster RG, Hay AJ, eds. Textbook of Influenza. London: Blackwell Science, 1998:219-64.

30. Hama R. Fatal neuropsychiatric adverse reactions to oseltamivir: Case series and overview of causal relationships. Internat J Risk Safety Med 2008;20:5-36.

31. Toovey S, Prinssen EP, Rayner CR, et al. Post-marketing assessment of neuropsychiatric adverse effects in influenza patients treated with oseltamivir: An updated review. Drug Safety 2008;31:1097-114.

32. Duval X, Vander Werf S, Bhanchan T, et al. Efficacy of oseltamivirzanamivir combinations compared to each monotherapy for seasonal influenza: A randomized, placebo-controlled trial. PLoS Med 2010; 7:e1000362.

33. Ariano RE, Sitar DS, Zelenitsky SA, et al. Enteric absorption and pharmacokinetics of oseltamivir in critically ill patients with pandemic (H1N1) influenza. Can Med Assoc J 2010;182:357-63.

34. South East Asia Infectious Disease Clinical Research Network. High-dose versus standard-dose oseltamivir for the treatment of severe influenza. Abstract P-205. Options for the Control of Influenza VII. Hong Kong, SAR China, 3-7 September 2010.

35. Kawai N, Ikematsu H, Iwaki N, et al. Zanamivir treatment is equally effective for both influenza $\mathrm{A}$ and influenza B (Lett). Clin Infect Dis 2007;44:1666.

36. FDA. Safety: Relenza (zanamivir) inhalation powder. 2009. $<$ www.fda.gov/Safety/MedWatch/SafetyInformation/ SafetyAlertsforHumanMedicalProducts/ucm186081> (Accessed August 2012).

37. Kim W-Y, Suh GY, Huh JW, et al. Triple-combination antiviral drug for pandemic H1N1 influenza virus infection in critically ill patients on mechanical ventilation. Antimicrob Ag Chemother 2011;55:5703-9.

38. Perelson AS, Rong L, Hayden FG. Combination antiviral therapy for influenza: predictions from modeling of human infections. J Infect Dis 2012;205:1642-5.

39. Jefferson T, Jones M, Dosho P, et al. Neuraminidase inhibitors for preventing and treating influenza in healthy adults: Systematic review and meta-analysis. BMJ 2009;339:b5106.

40. Matheson NJ, Harnden AR, Perera R, et al. Neuraminidase inhibitors for preventing and treating influenza in children. Cochrane Database Syst Rev 2007;(1):CD002744. DO1.10.1002/14651858.CD002744.pub2.

41. Falagas ME, Koletsi PK, Vouloumanon EK, et al. Effectiveness and safety of neuraminidase inhibitors in reducing influenza complications: A meta-analysis of randomized, controlled trials. J Antimicrob Chemother 2010;65:1330-46.

42. McGeer A, Green KA, Plevneski A, et al. Antiviral therapy and outcomes of influenza requiring hospitalization in Ontario, Canada. Clin Infect Dis 2007;45:1568-75.

43. Hayden FG. Influenza antivirals: Challenges and future directions. Plenary presentation. Options for the Control of Influenaza VII. Hong Kong, SAR China, 3-7 September 2010. <www. controlinfluenza.com/webcasts/optionsvii> (Accessed August 2012).

44. Calfee DP, Peng AW, Cass LM, et al. Safety and efficacy of intravenous zanamivir in preventing experimental human influenza A infection. Antimicrob Ag Chemother 1999;43:1616-20.

45. Gaur AH, Bagga B, Barman S, et al. Intravenous zanamivir for oseltamivir-resistant 2009 H1N1 influenza (Lett). N Engl J Med 2010;362:88-9.

46. Dulak DE, Williams JV, Creech CB, et al. Use of intravenous zanamivir after development of oseltamivir resistance in a critically 
ill immunosuppressed child with 2009 pandemic influenza A (H1N1) virus. Clin Infect Dis 2010;50:1493-6.

47. Fraay PL, van der Vries E, Beersma MF, et al. Evaluation of the antiviral response to zanamivir administered intravenously for treatment of critically ill patients with pandemic influenza A (H1N1) infection. J Infect Dis 2011;204:777-82.

48. CDC. Updated Recommendations for the use of Antiviral Medications in the Treatment and Prevention of Influenza for the 2009-2010 season. <www.cdc.gov/h1n1flu/recommendations.htm> (Accessed August 2012).

49. Aoki FY, Macleod MD, Paggiaro P, et al; on behalf of the IMPACT Study Group. Early administration of oral oseltamivir increases the benefits of influenza treatment. J Antimicrob Chemother 2003;51:123-9.

50. American Academy of Pediatrics. Influenza. In: Pickering LR, Baker CJ, Kimberlin DW, Long SS, eds. Red Book 2012 Report of the Committee on Infectious Diseases, 29th edn. Elk Grove Village: American Academy of Pediatrics, 2012:439-52.

51. Centers for Disease Control and Prevention. Influenza-associated pediatric deaths - United States, September 2010 - August 2011. Morb Mortal Wkly Rep 2011;60:1233-8.

52. MacDonald N, Onyett H, Bortolussi R. Managing seasonal and pandemic influenza in infants, children and youth <www.cps.cs/ english/publications/SeasonalPandemicFlu.pdf $>$ (Accessed August 2012).

53. Dawood FS, Subbarao K, Fiore AE. Influenza viruses. In: Long SS, Pickering LK, Prober CG, eds. Principle and Practice of Pediatric Infectious Diseases, 4th edition. Edinburgh: Elsevier Inc, 2012:1149-58.

54. Neuzil KM, Zhu Y, Griffin MR, et al. Burden of interpandemic influenza in children younger than 5 years: A 25-year prospective study. J Infect Dis 2002;185:147-52.

55. Shun-Shin M, Thompson M, Heneghan C, et al. Neuraminidase inhibitors for treatment and prophylaxis of influenza in children: Systematic review and meta-analysis of randomized controlled trials. BMJ 2009;3339; b3172. doi:10.1136/BMJ.b3172.

56. Whitley RJ, Hayden FG, Reisinger KS, et al. Oral oseltamivir treatment of influenza in children. Pediatr Infect Dis 2001;20:127-33.

57. Heinonen S, Silvennoinen H, Lehtinen P, et al. Early oseltamivir treatment of influenza in children 1-3 years of age. A randomized controlled trial. Clin Infect Dis 2010;51:887-94.

58. Johnston SL, Ferrero F, Garcia ML, et al. Oral oseltamivir improves pulmonary function and reduces exacerbation frequency for influenza-infected children with asthma. Pediatr Infect Dis 2005;24:225-32.

59. Kitching A, Roche A, Balasegaram S, et al. Oseltamivir adherence and side effects among children in three London schools affected by influenza A (H1N1)v, May 2009 - an internet-based cross-sectional survey. Euro Surveill 2009;14:19287.

60. Barr CE, Schulman K, Iacuzio D, et al. Effect of oseltamivir on the risk of pneumonia and use of health care services in children with clinically diagnosed influenza. Curr Med Res Opin 2007;23:523-31.

61. Piedra PA, Schulman KL, Blumentals WA. Effects of oseltamivir on influenza-related complications in children with chronic medical conditions. Pediatrics 2009;124:170-8.

62. Gums JG, Pelletier EM, Blumentals WA. Oseltamivir and influenzarelated complications, hospitalization and healthcare expenditure in healthy adults and children. Expert Opin Pharmacother 2008;9:151-61.

63. Kimberlin DW, Shalabi M, Abzug MJ, et al. Safety of oseltamivir compared with the adamantanes in children less than 12 months of age. Pediatr Infect Dis J 2010;29:195-8.

64. Acosta EP, Jester P, Gal P, et al. Oseltamivir dosing for influenza infection in premature neonates. J Infect Dis 2010;202:563-6.

65. WHO. Guidelines for pharmacological management of pandemic influenza A (H1N1) 2009 and other influenza viruses. Revised February 2010. Part I. Recommendations < www.who.int/csr/ resources/publications/swineflu/h1n1_guidelines_pharmaceutical_ mngt.pdf> (Accessed August 2012).

66. CDC. Interim Guidance on the use of influenza antiviral agents during the 2010-2011 influenza season. <www.cdc.gov/flu/ professionals/antivirals/guidance/> (Accessed August 2012).

67. Hackett S, Hill L, Patel J, et al. Clinical characteristics of pediatric H1N1 admissions in Birmingham, UK. The Lancet 2009;374:605.

68. Allen U, Doucette K, Bow E. Guidance on the management of pandemic H1N1 infection in immunocompromised individuals. <www.ammi.ca/pdf/guidelineh1N1.pdf> (Accessed August 2012).
69. Khanna N, Steffen I, Studt JD, et al. Outcome of influenza infections in outpatients after allogeneic hematopoietic stem cell transplantation. Transpl Infect Dis 2009;11:100-5.

70. O'Riordan S, Barton M, Yau Y, et al. Risk factors and outcomes among children admitted to hospital with pandemic H1N1 influenza. Can Med Assoc J 2010;182:33-44.

71. Couch RB, Englund JA, Whimbey E. Respiratory viral infections in immunocompetent and immunocompromised persons. Am J Med 1997;102(3A):2-9.

72. Gooskens J, Jonges M, Claas EC, et al. Prolonged influenza virus infection during lymphocytopenia and frequent detection of drugresistant viruses. J Infect Dis 2009;199:1435-41.

73. Cohen-Daniel L, Zakay-Rones Z, Resnick IB, et al. Emergence of oseltamivir-resistant influenza $\mathrm{A} / \mathrm{H} 3 \mathrm{~N} 2$ virus with altered hemagglutination pattern in a hematopoietic stem cell transplant recipient. J Clin Virol 2009;44:138-40.

74. Belshe RB, Gruber WC, Mendelman PM, et al. Correlates of immune protection induced by live, attenuated, cold-adapted, trivalent, intranasal influenza virus vaccine. J Infect Dis 2000;181:1133-7.

75. McMichael AJ, Gotch FM, Noble GR, et al. Cytotoxic T-cell immunity to influenza. N Engl J Med 1983; 309:13-17.

76. He X-S, Draghi M, Mahmood K, et al. T cell-dependent production of IFN $-\gamma$ by NK cells in response to influenza A virus. J Clin Invest 2004;114:1812-19.

77. Stuck AE, Minder CE, Frey FJ. Risk of infectious complications in patients taking glucocorticosteroids. Rev Infect Dis 1989;11:954-63.

78. American Academy of Pediatrics. Immunization in special clinical circumstances. In: Pickering LR, Baker CJ, Kimberlin DW, Long SS, eds. Red Book 2012 Report of the Committee on Infectious Diseases, 28th edn. Elk Grove Village: American Academy of Pediatrics, 2012:83.

79. Kumar D, Michaels MG, Morris M, et al. A multicenter study of outcomes from pandemic influenza A/H1N1 infection in solid organ transplant recipients. Lancet Infect Dis 2010;10:521-6.

80. Dodds L, McNeil SA, Fell SB, et al. Impact of influenza exposure on rates of hospital admissions and physician visits because of respiratory illness among pregnant women. Can Med Assoc J 2007; $176: 463-8$.

81. Siston AM, Rasmussen SA, Honein MA, et al. Pandemic 2009 influenza A (H1N1) virus illness among pregnant women in the United States. JAMA 2010;303:1517-25.

82. Pierce M, Kurinczuk JJ, Spark P, et al. Perinatal outcomes after maternal 2009/H1N1 infection: National cohort study. BMJ 2011;342:d3214 doi:10.1136/bmj.d3214.

83. Greer LG, Leff RD, Laibi-Rogers V, et al. Pharmacokinetics of oseltamivir according to trimester of pregnancy. Am J Obstet Gynecol 2011;204S89-S93.

84. Greer LG, Leff RD, Laibl-Rogers V, et al. Pharmacokinetics of oseltamivir in breast milk and maternal plasma. Am J Obstet Gynecol 2011;204:524.e1-4.

85. Louie JK, Acosta M, Jamieson DJ, et al. Severe 2009 H1N1 influenza in pregnant and postpartum women in California. N Engl J Med 2010;362:27-35.

86. Tanaka T, Nakajima K, Murashima A, et al. Safety of neuraminidase inhibitors against novel influenza A (H1N1) in pregnant and breastfeeding mothers. Can Med Assoc J 2009;181:55-8.

87. Donner B, Nianjan V, Hoffmann G. Safety of oseltamivir in pregnancy: A review of preclinical and clinical data. Drug Safety 2010;33:631-42.

88. Thorner AR. Treatment of pandemic H1N1 influenza ('swine influenza'). Up To Date. <www.uptodate.com> (Accessed August 2012).

89. Public Health Branch, Health Services Sector. CSC interim guidance for managing seasonal influenza and novel influenza viruses including pandemic (H1N1). 2009 (Version 3).

90. Interim Guidance for Correctional and Detention Facilities on Novel Influenza A (H1N1) Virsu, May 24, 2009. <www.cdc.gov/h1n1flu/ guidance/correctional_facilities.htm>. (Accessed August 2012).

91. Webster A, Boyce M, Edmundson S, et al. Coadministration of orally inhaled zanamivir with inactivated trivalent influenza vaccine does not adversely affect the production of antihemagglutinin antibodies in the serum of healthy volunteers. Clin Pharmacokinet 1999;36(Suppl 1):51-8.

92. Hui CPS, McDonald NE; the Infectious Diseases and Immunization Committee, Canadian Paediatric Society. The use of influenza vaccine in children with egg allergies. Paediatr Child Health 2011;16:491-2. 


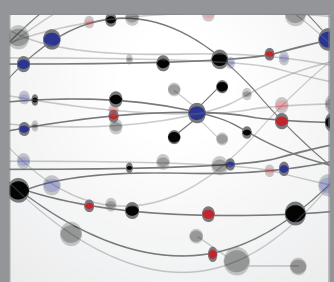

The Scientific World Journal
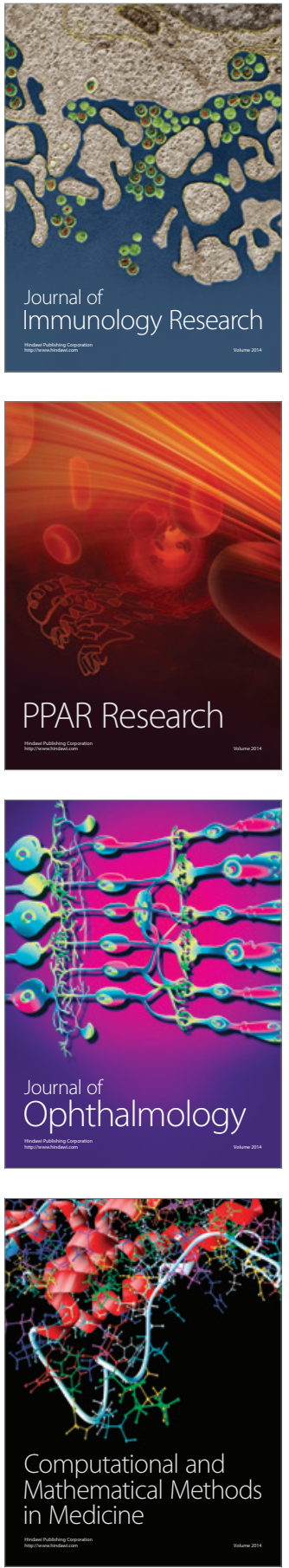

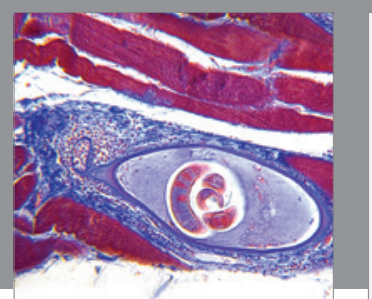

Gastroenterology Research and Practice

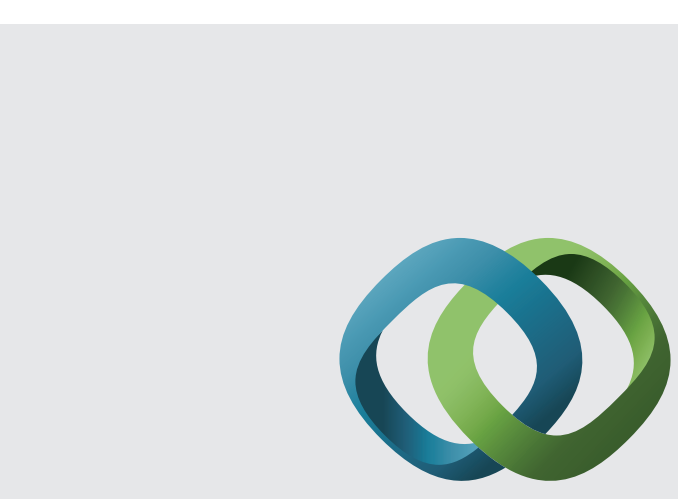

\section{Hindawi}

Submit your manuscripts at

http://www.hindawi.com
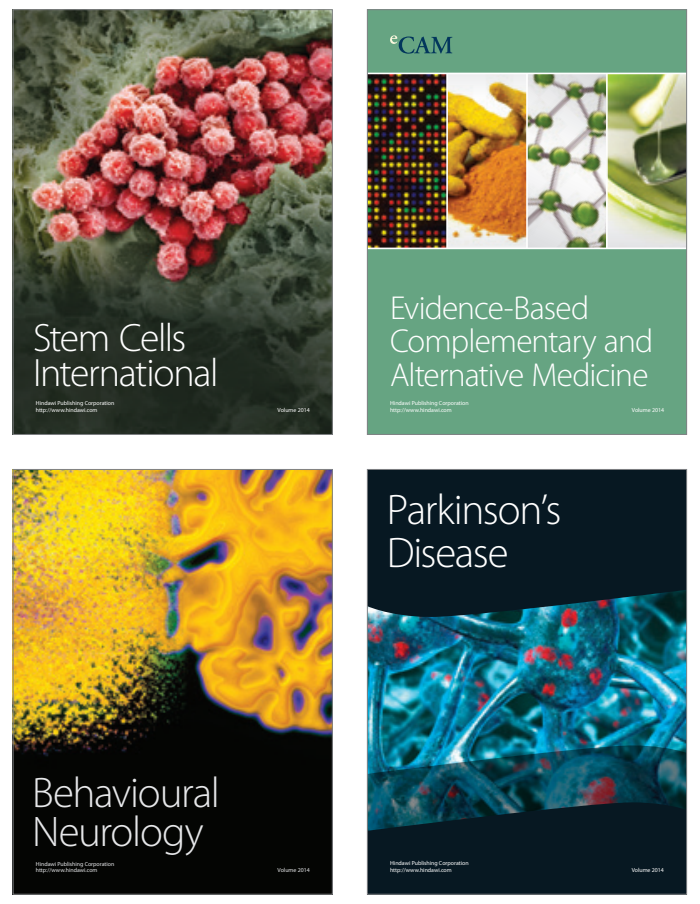
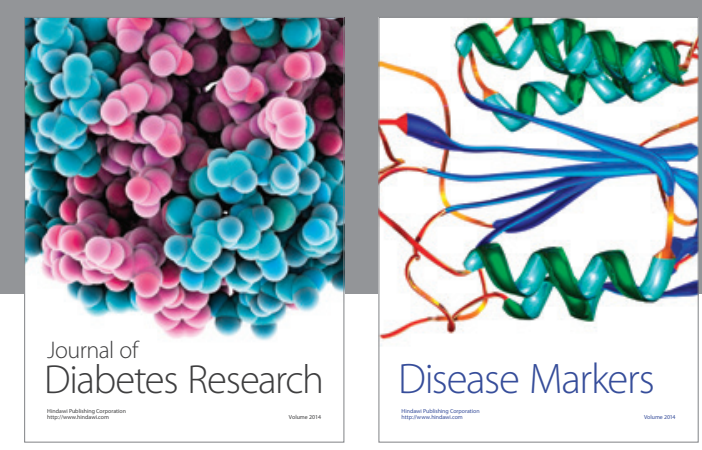

Disease Markers
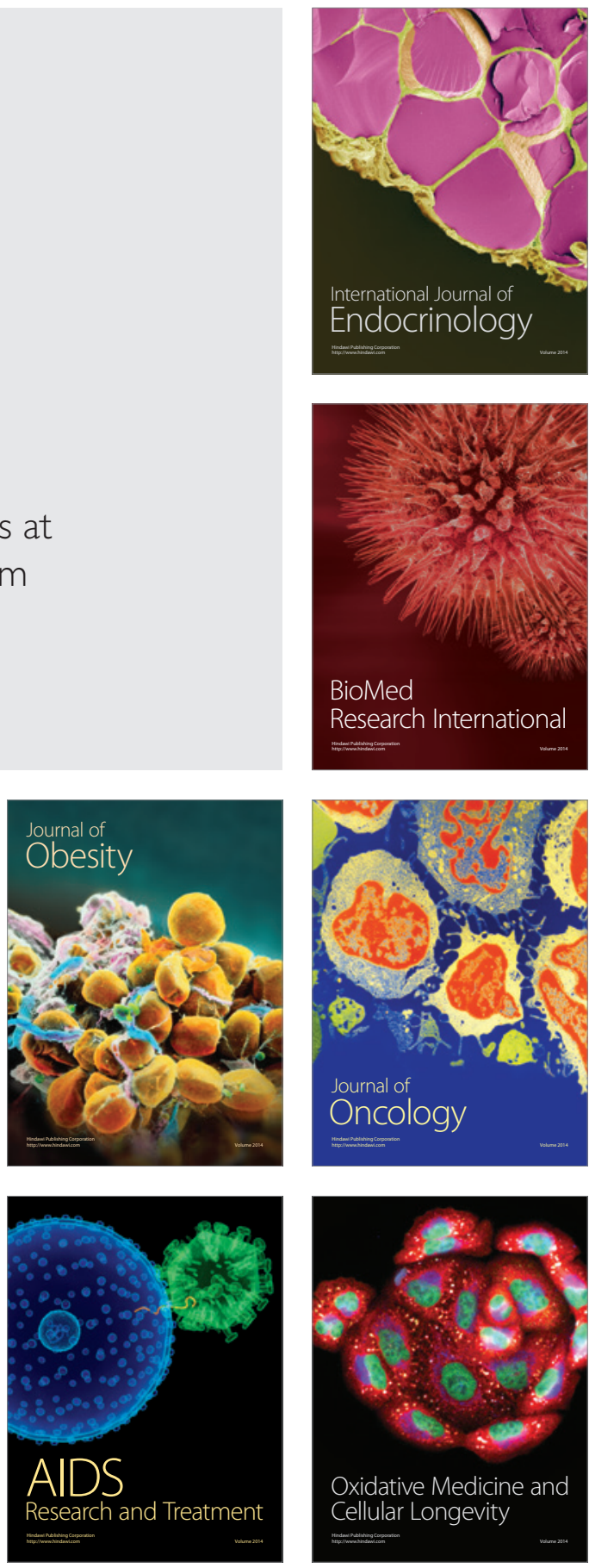